\title{
Design, Synthesis, and Biological Evaluation of Potent Quinoline and Pyrroloquinoline Ammosamide Analogues as Inhibitors of Quinone Reductase ${ }^{\dagger}{ }^{\dagger}$
}

\author{
P. V. Narasimha Reddy $\ddagger$ Katherine C. Jensen $§$, Andrew D. Mesecar§, Phillip E. Fanwickף, \\ and Mark Cushman ${ }^{\star}, \neq$ \\ FDepartment of Medicinal Chemistry and Molecular Pharmacology, College of Pharmacy, and \\ The Purdue University Center for Cancer Research, Purdue University, West Lafayette, Indiana \\ 47907 \\ §Departments of Biological Sciences and Chemistry, and The Purdue University Center for \\ Cancer Research, Purdue University, West Lafayette, Indiana 47907
}

IDepartment of Chemistry, Purdue University, West Lafayette, Indiana 47907

\section{Abstract \\ A variety of ammosamide B analogues have been synthesized and evaluated as inhibitors of quinone reductase $2(\mathrm{QR} 2)$. The potencies of the resulting series of $\mathrm{QR} 2$ inhibitors range from 4.1 to $25,200 \mathrm{nM}$. The data provide insight into the structural parameters necessary for QR2 inhibitory activity. The natural product ammosamide B proved to be a potent QR2 inhibitor, and the potencies of the analogues generally decreased as their structures became more distinct from that of ammosamide B. Methylation of the 8-amino group of ammosamide B was an exception, resulting in an increase in quinone reductase 2 inhibitory activity from $\mathrm{IC}_{50}$ of $61 \mathrm{nM}$ to $\mathrm{IC}_{50} 4.1$ $\mathrm{nM}$.}

\section{Introduction}

Ammosamides A-C are metabolites isolated from the marine Streptomyces strain CNR-698. ${ }^{1-3}$ All three natural products are thought to modulate tubulin and actin dynamics through myosin binding. ${ }^{2,4}$ The administration of a fluorescent ammosamide B conjugate to HCT-116 cells results in the depolymerization of microtubules and an increase in actin filaments, and histological staining is consistent with the binding of the conjugate to several myosin families. ${ }^{4}$<smiles></smiles>

Ammosamide A (1, X = S) Ammosamide $B(2, X=O)$<smiles>[CH2-][N+]1=Cc2cc(C(N)=O)nc3c(N)c(Cl)c(N)c1c23</smiles>

Ammosamide C (3)

†PDB code for ammosamide B (2) with QR2, QUXH; PDB code for 38 with QR2, 3UXE.

*To whom correspondence should be addressed. Tel: 765-494-1465. Fax: 765-494-6790. cushman@purdue.edu..

Supporting Information Available: Crystallographic data for compound 34, gene expression profile for QR2 in the NCI-60 cell lines (Figure S2), and Fo-Fc electron density omit maps for ammosamide B and compound $\mathbf{3 8}$ (Figure S3). 
Two conceptually distinct syntheses of ammosamide B have recently been reported. ${ }^{3,5}$ Our synthesis relies on the condensation of the diprotected 1,3,4,6-tetraaminobenzene derivative 4 with the di(methylester) of 2-ketoglutaconic acid (5) to produce the ammosamide framework $\mathbf{6}$ as the key step (Scheme 1). ${ }^{5}$ As reported in the present communication, this synthesis has proven to be quite short and flexible, allowing the production of a focused library of ammosamide congeners that have been evaluated as inhibitors of quinone reductase 2 .

X-ray crystallographic-assisted dereplication methods have revealed that the ammosamides have potent quinone reductase 2 (QR2) inhibitory activity. ${ }^{6}$ The FAD-dependent flavoenzyme QR2 catalyzes the reduction of quinones by reduced $\mathrm{N}$-alkyl- and $\mathrm{N}$ ribosylnicotinamides. ${ }^{7} \mathrm{QR} 2$ is capable of transforming some quinone substrates into highly reactive species that damage cells. ${ }^{7-9}$ Inhibition of QR2 could therefore conceivably protect cells from chemical damage. ${ }^{10} \mathrm{~A}$ number of QR2 inhibitors have been reported, ${ }^{11-20}$ and the structures of QR2 in complex with a number of inhibitors have been determined by X-ray crystallography. ${ }^{11,21-26}$ The present study was motivated by the idea that novel and potent QR2 inhibitors could be generated based on the structures of the ammosamides and that these inhibitors could be possibly be of value as cancer chemopreventive agents.

\section{Results and Discussion}

\section{Synthesis of Ammosamide Analogues}

Our synthesis of ammosamide B provided sufficient material for evaluation of its biological properties, and it also enabled the synthesis of an array of structural analogues of value in the investigation of structure-activity relationships.27 As outlined in Scheme 2, the substituted quinoline 9 was obtained by monoprotection of $\mathbf{7}$ using benzyl chloroformate followed by condensation of the product 8 with compound $\mathbf{5}$. The quinoline 9 proved to be a versatile intermediate that could be converted to a number of derivatives. Hydrogenation of quinoline 9 at $30 \mathrm{psi}$ for $1 \mathrm{~h}$ afforded the free amine 10, which reacted with $\mathrm{N}$ chlorosuccinimide (NCS) to afford the dichloroquinoline 11. Treatment of $\mathbf{1 0}$ with $30 \%$ ammonium hydroxide in THF at room temperature afforded the C-2 amide 12, while acetylation of $\mathbf{1 0}$ provided $\mathbf{1 3}$, which could be converted to the corresponding C-2 amide $\mathbf{1 4}$ in good yield. Quinoline 10 on reaction with $\mathrm{MeI}$ and $\mathrm{NaH}$ in DMF yielded the corresponding $N, N$-dimethylated quinoline $\mathbf{1 5}$ in $80 \%$ yield, which on treatment with $30 \%$ aq ammonia afforded the corresponding C2 amide 16 in 95\% yield. As outlined in Scheme 3 , reaction of the starting material $17^{28}$ with compound $\mathbf{5}$ resulted in the cyclized intermediate 18, which was converted to 19 and $\mathbf{2 0}$ with ammonium hydroxide in THF. Quinoline 22, obtained by condensation of $\mathbf{2 1}$ with $\mathbf{5}$, reacted with aq $30 \% \mathrm{NH}_{3}$ in THF for $24 \mathrm{~h}$ to afford the corresponding C2 amide $\mathbf{2 3}$ (Scheme 4).

Intermediate $25^{5}$ was obtained by reduction of the starting material $\mathbf{2 4}$ with iron and ammonium chloride in aq DMF at $100{ }^{\circ} \mathrm{C}$ (Scheme 5). Reaction of 25 with (E)-dimethyl 4oxopent-2-enedioate (5) in the presence of $p$-toluenesulfonic acid (PTSA) and cupric acetate in methylene chloride afforded compound 26, which on treatment with $\mathrm{NaH}$ in THF at room temperature produced 33. On the other hand, reaction of $\mathbf{2 6}$ with $\mathrm{SOCl}_{2}$ provided the expected quinoline 27 in very high yield. Quinoline 27 on treatment with $\mathrm{Et}_{3} \mathrm{~N}$ in $\mathrm{CH}_{2} \mathrm{Cl}_{2}$ resulted in the formation of corresponding pyrroloquinoline $\mathbf{2 8}$, which on methylation with MeI, using NaH in DMF as the base, afforded the $N$-methylpyrroloquinoline compound 29 in $92 \%$ yield. Compound $\mathbf{2 9}$ on treatment with $30 \%$ aq ammonia in THF at room temperature for $24 \mathrm{~h}$ resulted in corresponding amide compound 30. Deprotonation of the amide 30 with $n$-butyllithium in THF, followed by reaction with benzyl bromide, afforded the benzylamide 31. On the other hand, deprotonation of $\mathbf{3 0}$ with sodium hydride in DMF, followed by alkylation with methyl iodide, yielded the corresponding $\mathrm{N}, \mathrm{N}$-dimethylamide 
32. Surprisingly, attempted nitration of the pyrroloquinoline 29 with $\mathrm{HNO}_{3}$ and $\mathrm{H}_{2} \mathrm{SO}_{4}$ afforded the ortho quinone $\mathbf{3 4}$ instead, as confirmed by X-ray crystallography (see Supporting Information).

The synthesis of the ammosamide analogue 38 is outlined in Scheme 6. Deprotonation of compound $\mathbf{3 5}^{5}$ with sodium hydride in DMF, followed by alkylation with methyl iodide, afforded a mixture of the products $\mathbf{3 6}^{5}$ in $70 \%$ yield and $\mathbf{3 7}$ in $15 \%$ yield. The methyl ester $\mathbf{3 7}$ was then converted to the amide $\mathbf{3 8}$ by treatment with ammonia in THF.

\section{Inhibition of Quinone Reductase 2 by Tricyclic Ammosamide Analogues}

The QR2 inhibitory activities of the tricyclic ammosamide analogues are summarized in Table 1, while the inhibitory activities of a series of bicyclic compounds are summarized in Table 2. The lead compound 2, or ammosamide B, was previously shown be a potent QR2 inhibitor with an $\mathrm{IC}_{50}$ value of $61 \mathrm{nM}^{6}{ }^{6}$ Removal of the $\mathrm{R}^{3}$ chlorine atom and substitution of the $\mathrm{R}^{2}$ and $\mathrm{R}^{4}$ amines with chlorines in analogue 30 decreased the inhibitory potency 95 fold. Modification of the $\mathrm{R}^{5}$ group of $\mathbf{3 0}$ further reduced the inhibitory potency as observed with analogues $\mathbf{3 1}$ and $\mathbf{3 2}$. Solubility issues with the dichloro analogues (27, and 30-32) confounded the kinetic studies and are likely the reason complete inhibition (\%max inhibition $<50 \%$ ) of QR2 could not be obtained.

Additional compounds, including $\mathbf{2 6}$ and $\mathbf{3 3}$, were tested but none showed inhibitory activity against QR2. The lack of inhibition by these compounds may be due to their absence of structural planarity. The active site of QR2 in general prefers planar, rigid ligands that are capable of stacking with the planar flavin ring system of the FAD cofactor. Therefore, removal of structural planarity in inhibitor analogues tends to destroy this interaction. ${ }^{23}$ The orthoquinone $\mathbf{3 4}$ was found to be too reactive with the $N$-methyldihydronicotinamide (NMeH) cofactor in the absence of enzyme and therefore could not be tested as an inhibitor with the QR2 system. The only tricyclic ammosamide analogue that showed improved inhibitory potency compared to ammosamide $\mathrm{B}$ was $\mathbf{3 8}$. Methylation of the amine group at $\mathrm{R}^{4}$ increased the potency towards QR2 around $15-$ fold ( $4.1 \mathrm{nM}$ versus $\left.61 \mathrm{nM}\right)$.

\section{X-ray Structures of QR2 in Complex with 2 and 38}

In an attempt to gain structural insight into the potent inhibition of QR2 by compounds 2 and 38, the X-ray crystal structures of these complexes were determined. QR2 crystallized in space group $\mathrm{P} 2{ }_{1} 2_{1} 2_{1}$ and contained one dimer per asymmetric unit. Complete $\mathrm{X}$-ray data sets were collected and refined to $1.53 \AA$ and $1.50 \AA$ for the complexes containing compounds $\mathbf{2}$ and $\mathbf{3 8}$, respectively. Strong electron density is observed for compounds $\mathbf{2}$ and 38 as well as for a number of water molecules associated with the inhibitors (Figures 1a and b). Both compounds bind to QR2 in identical orientations sitting directly above and interacting with the FAD cofactor. Two direct hydrogen bonds are observed between the primary amide group of the inhibitors $\left(\mathrm{R}^{5}\right.$ position) and the amide $-\mathrm{NH}_{2}$ group of Asn 161 . In addition, both compounds form water-mediated hydrogen bonds to the side chain - $\mathrm{OH}$ group of Thr71 via their $-\mathrm{NH}_{2}$ groups at the $\mathrm{R}^{2}$ position. Interestingly, the amide group at the $\mathrm{R}^{5}$ position, the amine group at the $\mathrm{R}^{4}$ position, and the nitrogen in the ring of the inhibitor all form hydrogen bonds with an ordered active site water molecule that is hydrogen bonded to the backbone carbonyl oxygen of Gly174 (not shown). This water molecule is present in the active site of unliganded QR2 and is typically displaced by the binding of inhibitors. ${ }^{22}$ The utilization of this water molecule for formation of a hydrogen bond with QR2 may contribute to the nanomolar potency.

The X-ray structures of QR2 in complex with compounds $\mathbf{2}$ and $\mathbf{3 8}$ are superimposed in Figure 1c to gain structural insight into the improved potency of compound $\mathbf{3 8}$ over $\mathbf{2}$. The 
binding orientations of the two inhibitors within the QR2 active site are identical within the coordinate error of the $\mathrm{X}$-ray structures. As a result, we cannot explain structurally why the additional methyl group at the $\mathrm{R}^{1}$ position of compound $\mathbf{3 8}$ leads to the greater than 10 -fold increase in potency compared to that of compound $\mathbf{2}$. However, there is one observable difference between the active sites of the two structures. There are 7 highly ordered water molecules observed in the active site of the QR2-compound $\mathbf{2}$ complex whereas there are only 5 water molecules observed in the QR2-compound $\mathbf{3 8}$ complex. We independently determined three X-ray structures of the QR2-compound $\mathbf{3 8}$ complex from different crystals and all show the same number of water molecules suggesting that the disappearance of the two water molecules for compound $\mathbf{3 8}$ is likely not an artifact of soaking or flash-freezing the crystals. Therefore, the loss of the 2 water molecules may provide some entropic gain for the QR2-compound 38 complex thereby improving its potency. The importance of active site water molecules in QR2 inhibitor binding has recently been notes for a series of imidazoacridin-6-ones. ${ }^{20}$

\section{Inhibition of Quinone Reductase 2 by Bicyclic Ammosamide Analogues}

To further explore the structural space surrounding the ammosamides, we designed and synthesized a series of bicyclic ammosamide derivatives and tested their inhibitory potency against human QR2. The structures of the analogues and their associated inhibitory potencies are summarized in Table 2. A comparison of the activities of a number of the bicyclic compounds documents a regular increase in biological activity when the C-2 methyl ester is converted into a primary amide and the rest of the structure is constant. Examples of this effect include $\mathbf{1 0}$ vs. 12 (IC 503.3 vs. $1.1 \mu \mathrm{M}$ ), $\mathbf{1 5}$ vs. $\mathbf{1 6}$ (IC50 4.0 vs. $1.6 \mu \mathrm{M}$ ), $\mathbf{1 3}$ vs. 14 (>100 vs. $9.0 \mu \mathrm{M}$ ), and 22 vs. 23 ( $\mathrm{IC}_{50} 0.24$ vs. $0.15 \mu \mathrm{M}$ ). Similarly, the conversion of a hydrogen of $\mathbf{1 2}$ into a primary amine at the $\mathrm{R}^{6}$ position of $\mathbf{2 3}$ results in a 10-fold increase in activity ( $\mathrm{IC}_{50} 1.1$ vs. $0.15 \mu \mathrm{M}$ ) and the most potent bicyclic compound. The primary amide substituent of $\mathbf{2 3}$ parallels the substitution of the two most potent bicyclic compounds, $\mathbf{2}$ and 38. The conversion of the 7-amino group in $\mathbf{1 0}$ to a dimethylamino group in $\mathbf{1 5}$ is well tolerated, as observed by their comparable $\mathrm{IC}_{50}$ values $\left(\mathrm{IC}_{50} 3.3\right.$ vs. $\left.4.0 \mu \mathrm{M}\right)$. The addition of a second chlorine at the 8-position, 11, as compared to 10, results in only a slight decrease in potency $\left(\mathrm{IC}_{50} 3.3\right.$ vs. $5.6 \mu \mathrm{M}$ ). The effect of acetylating the 7-amino group decreases activity as documented by comparison of $\mathbf{1 2}$ vs. $\mathbf{1 4}\left(\mathrm{IC}_{50} 1.1\right.$ vs. $\left.9.0 \mu \mathrm{M}\right)$. Additionally, acetylation at R7 in compound $\mathbf{1 3}$ drastically decreases activity as compared to compound $10\left(\mathrm{IC}_{50}>100 \mu \mathrm{M}\right.$ vs. $\left.3.3 \mu \mathrm{M}\right)$. Conversion of the methyl ester at C-4 in 19 to the amide in 20 causes only a slight increase in activity ( $\mathrm{IC}_{50} 1.8$ vs. $\left.1.5 \mu \mathrm{M}\right)$.

QR2 inhibitors are in general planar aromatic compounds that can stack with the planar flavin moiety of the co-factor in the active site. ${ }^{11-20}$ These structural requirements are similar to those involved in DNA intercalation, and indeed, some QR2 inhibitors have been found to be cytotoxic due to a DNA intercalation mechanism. ${ }^{20}$ In addition, the ammosamides were originally isolated by cytotoxicity-guided (HCT-116) fractionation, further suggesting that the present series of compounds could be cytotoxic. ${ }^{2}$ The compounds were therefore submitted to the NCI panel of 60 human cancer cell lines for cytotoxicity evaluation. ${ }^{29-31}$ As documented in Table 3 , all of the compounds were surprisingly noncytotoxic at a concentration of $10 \mu \mathrm{M}$. These data are in agreement with results indicating that QR2 inhibitors that do not have off-target effects should generally not be cytotoxic. ${ }^{20}$

The expression levels of QR2 have been documented in both normal and transformed prostate cells. ${ }^{32,33}$ While QR2 is expressed at levels that are below the limits of detection in normal prostate epithelial cells (PrECs), it had robust levels of expression in normal prostate stromal cells (PrSCs). ${ }^{32}$ Furthermore, PrSCs were subject to dose-dependent inhibition of cellular proliferation by the QR2 inhibitor resveratrol. ${ }^{11,18,34}$ On the other hand, resveratrol had no effect on PrEC growth. This has led to the hypothesis that QR2 has a role in control 
of cellular proliferation by resveratrol in PrSCs. ${ }^{32}$ According to this idea, the lack of toxicity of the ammosamide analogues shown in Table 3 might therefore have something to do with low levels of QR2 expression. This unlikely possibility can be eliminated in the case of DU-145 prostate cancer cells because QR2 has been detected in significant levels in DU-145 cells, as well as in LNCaP, CWR22Rv1, PC-3 and JCA1 prostate cancer cells. ${ }^{33}$

Furthermore, significant expression levels of QR2 have been documented in all of the other cell lines listed in Table 3 (see Supporting Information, Figure S2). The lowest QR2 expression rate is in HOP-62 cells, while the highest rate is in HCT-116 cells.

In conclusion, a series of ammosamide B analogues were designed, synthesized and tested of their inhibitory potency against human quinone reductase 2 but only one analogue was found to have improved potency over the natural product. The simple methylation of the amine at the $\mathrm{R}^{4}$ position of $\mathbf{2}$ producing compound $\mathbf{3 8}$ improved potency over 10 -fold. X-ray structural analysis of the QR2 bound with these inhibitors suggests that since no differences are observed in the binding orientations of the inhibitors, that the differences in potencies may potentially be attributed to a difference in entropy produced by binding of fewer water molecules in the active site of the QR2-38 complex. However, further thermodynamic measurements would need to be made in order to quantify any differences.

The present series of QR2 inhibitors are structurally reminiscent of the known QR2 inhibitors primaquine, chloroquine, quinacrine, and mefloquine, which are also quinoline derivatives. ${ }^{12,19}$

\section{Experimental Section}

\section{General Procedures}

Melting points were determined in capillary tubes using a Mel-Temp apparatus and are not corrected. Infrared spectra were obtained as films on $\mathrm{KBr}$ salt plates except where otherwise specified, using a Perkin-Elmer Spectrum One FT-IR spectrometer, and are baseline corrected. ${ }^{1} \mathrm{H}$ NMR spectra were obtained with $\mathrm{CDCl}_{3}$ at 300 or $500 \mathrm{MHz}$, using Bruker ARX300 or Bruker Avance 500 (TXI $5 \mathrm{~mm}$ probe) spectrometers (residual chloroform referenced to $7.25 \mathrm{ppm}$ ) or DMSO- $d_{6}$ (residual DMSO referenced to $2.49 \mathrm{ppm}$ and residual water in DMSO- $d_{6}$ appearing at $\left.3.33 \mathrm{ppm}\right) .{ }^{13} \mathrm{C} \mathrm{NMR}$ spectra were recorded with $\mathrm{CDCl}_{3}$ at $75 \mathrm{MHz}$ or $125 \mathrm{MHz}$, using Bruker ARX300 or Bruker Avance 500 (TXI $5 \mathrm{~mm}$ probe) spectrometers (residual chloroform referenced to $77.0 \mathrm{ppm}$ ) or DMSO- $d_{6}$ (residual DMSO referenced to $39.5 \mathrm{ppm}$ ). Mass spectral analyses were performed at the Purdue University Campus-Wide Mass Spectrometry Center. ESIMS was performed using a FinniganMAT LCQ Classic mass spectrometer system. EI/CIMS was performed using a Hewlett-Packard Engine or GCQ FinniganMAT mass spectrometer system. Analytical thin-layer chromatography was carried out on Baker-flex silica gel IB2-F plastic-backed TLC plates. Preparative thin-layer chromatography was performed on Analtech silica gel $1500 \mu \mathrm{m}$ glass plates. Compounds were visualized with both short- and long-wavelength UV light. Silica gel flash chromatography was accomplished using 230-400 mesh silica gel. All yields reported refer to yields of isolated compounds. Unless otherwise stated, chemicals and solvents were of reagent grade and used as obtained from commercial sources without further purification. The intensity of the major peak in the analytical HPLC trace of each target compound was $\geq 95 \%$ that of the combined intensities of all of the peaks detected at $254 \mathrm{~nm}$ on a reversed-phase C18 HPLC column.

\section{General Procedure for Quinoline Formation}

A solution of $(E)$-dimethyl 4-oxopent-2-enedioate (5) (1.2 eq) in dichloromethane (20 mL) was added to a solution of amine in dichloromethane $(10 \mathrm{~mL} / 0.1 \mathrm{mmol})$ and the reaction mixture stirred for $30 \mathrm{~min}$. A catalytic amount of PTSA ( $0.1 \mathrm{eq})$ was added and the solution 
was heated at reflux for $24 \mathrm{~h}$. The reaction mixture was washed 3 times with $\mathrm{NaHCO}_{3}(15$ $\mathrm{mL}$ ). The organic layer was separated and dried over $\mathrm{Na}_{2} \mathrm{SO}_{4}$ and purified by silica gel column chromatography.

\section{General Procedure for Carboxamide Formation}

Diester was dissolved in THF $(20 \mathrm{~mL})$ and a $30 \% \mathrm{NH}_{4} \mathrm{OH}$ solution $(2 \mathrm{~mL})$ was added. The reaction mixture stirred at room temperature for $24 \mathrm{~h}$, by which time all of the ester had been converted to amide. THF was removed on a rotary evaporator, $\mathrm{CHCl}_{3}(15 \mathrm{~mL})$ was added, and the mixture was washed with water $(2 \times 10 \mathrm{~mL})$. The combined organic layer was dried over $\mathrm{Na}_{2} \mathrm{SO}_{4}$, and then concentrated to get the amide in quantitative yield.

\section{Benzyl 3-Amino-5-chlorophenylcarbamate (8)}

DIPEA (0.54 g, $4.1 \mathrm{mmol})$ was added to a stirred solution of diamine $7(0.2 \mathrm{~g}, 1.40 \mathrm{mmol})$ in $\mathrm{CH}_{2} \mathrm{Cl}_{2}(10 \mathrm{~mL})$ at room temperature and the reaction mixture stirred at room temperature for $30 \mathrm{~min}$. Benzyl chloroformate $(0.216 \mathrm{~mL}, 1.54 \mathrm{mmol})$ was added and the reaction mixture was stirred for $24 \mathrm{~h}$. The reaction mixture was extracted with $\mathrm{CH}_{2} \mathrm{Cl}_{2}(2 \times$ $20 \mathrm{~mL}$ ) and washed with aq $\mathrm{NH}_{4} \mathrm{Cl}$. The organic layer was concentrated and purified by silica gel column chromatography using hexane-EtOAc 1:1 to afford the product $\mathbf{8}$ as white solid $(0.230 \mathrm{~g})$ in $60 \%$ yield. ${ }^{1} \mathrm{H}$ NMR $(\mathrm{CDCl} 3,300 \mathrm{MHz}) \delta$ 7.36-7.32 $(\mathrm{m}, 5 \mathrm{H}), 6.75(\mathrm{~s}, 1$ $\mathrm{H}), 6.65(\mathrm{~s}, 2 \mathrm{H}), 6.34(\mathrm{~s}, 1 \mathrm{H}), 5.15(\mathrm{~s}, 2 \mathrm{H}), 3.72(\mathrm{br} \mathrm{s}, 1 \mathrm{H})$.

\section{Dimethyl 7-(Benzyloxycarbonylamino)-5-chloroquinoline-2,4-dicarboxylate (9)}

This compound was prepared using the general procedure for carboxamide formation detailed above: $\mathrm{mp} 123-125^{\circ} \mathrm{C}$. IR (KBr) 3366, 2978, 1712, 1702, 1238, 1221, 783, 729, $656 \mathrm{~cm}^{-1} ;{ }^{1} \mathrm{H}$ NMR $\left(\mathrm{CDCl}_{3}, 300 \mathrm{MHz}\right) \delta 8.23(\mathrm{~s}, 1 \mathrm{H}), 8.05-8.03(\mathrm{~m}, 2 \mathrm{H}), 7.40-7.37(\mathrm{~m}, 5$ $\mathrm{H}), 7.10(\mathrm{~s}, 1 \mathrm{H}), 5.22(\mathrm{~s}, 2 \mathrm{H}), 4.04(\mathrm{~s}, 3 \mathrm{H}), 4.00(\mathrm{~s}, 3 \mathrm{H}) ;{ }^{13} \mathrm{C} \mathrm{NMR}\left(\mathrm{CDCl}_{3}, 75 \mathrm{MHz}\right) \delta$ 165.7, 165.2, 153.4, 147.9, 141.3, 136.4, 132.6, 130.0, 128.5, 120.0, 127.8, 125.5, 125.0, $118.2,114.5,111.8,66.2,51.5$; ESIMS $\left(\mathrm{m} / z\right.$, relative intensity) $429\left(\mathrm{MH}^{+}, 100\right), 431\left(\mathrm{MH}^{+}\right.$, 35, chlorine isotope), 490 (64); HRMS calcd for $\mathrm{C}_{21} \mathrm{H}_{17} \mathrm{ClN}_{2} \mathrm{O}_{6} 428.0775$, found 428.0779.

\section{Dimethyl 7-Amino-5-chloroquinoline-2,4-dicarboxylate (10)}

A mixture of CBz-protected amine $9(0.05 \mathrm{~g}, 0.17 \mathrm{mmol})$ and $10 \%$ Pd-C catalyst $(20 \mathrm{mg})$ in EtOAc-MeOH (1:1) $(4 \mathrm{~mL})$ was hydrogenated at $30 \mathrm{psi}$ for $1 \mathrm{~h}$. The suspension was filtered and the filtrate was evaporated and then purified by silica gel column chromatography, with hexane-EtOAc, 6:4 to get the amine $\mathbf{1 0}(0.030 \mathrm{~g})$ in $95 \%$ yield as yellowish solid: $\mathrm{mp}$ 153-155 ${ }^{\circ} \mathrm{C}$. IR (KBr) 3372, 2953, 1724, 1708, 1612, 1259, 1232, 789, 726, $643 \mathrm{~cm}^{-1} ;{ }^{1} \mathrm{H}$ NMR $\left(\mathrm{CDCl}_{3}, 300 \mathrm{MHz}\right) \delta 7.88(\mathrm{~s}, 1 \mathrm{H}), 7.33(\mathrm{~d}, J=2.1 \mathrm{~Hz}, 1 \mathrm{H}), 7.19(\mathrm{~d}, J=2.1 \mathrm{~Hz}, 1 \mathrm{H})$, 4.25 (br s, $2 \mathrm{H}), 4.04$ (s, $3 \mathrm{H}), 3.98$ (s, $3 \mathrm{H}) ;{ }^{13} \mathrm{C} \mathrm{NMR}\left(\mathrm{CDCl}_{3}, 75 \mathrm{MHz}\right) \delta 166.3,165.6$, 150.6, 148.3, 147.6, 135.4, 126.4, 122.4, 120.1, 118.7, 109.9, 53.1, 52.7; ESIMS $(\mathrm{m} / \mathrm{z}$, relative intensity) $\left.295\left(\mathrm{MH}^{+}, 100\right)\right], 297\left(\mathrm{MH}^{+}, 33\right.$, chlorine isotope), 233 (62), 260 (51), 282 (49); HRMS calcd for $\mathrm{C}_{13} \mathrm{H}_{11} \mathrm{ClN}_{2} \mathrm{O}_{4} 295.0486$, found 295.0480.

\section{Dimethyl 7-Amino-5,8-dichloroquinoline-2,4-dicarboxylate (11)}

Compound 10 (0.05 g, $0.116 \mathrm{mmol})$ was taken in $\mathrm{CH}_{3} \mathrm{CN}(4 \mathrm{~mL})$ and NCS $(0.020 \mathrm{~g}, 0.140$ $\mathrm{mmol}$ ) was added at room temperature and reaction mixture heated at $65^{\circ} \mathrm{C}$ for $2 \mathrm{~h}$. Ethyl acetate $(10 \mathrm{~mL})$ was added to the mixture, and the solution was washed with aq $\mathrm{NaHCO}_{3}(5$ $\mathrm{mL})$. The water layer was extracted again with EtOAc $(10 \mathrm{~mL})$ and the solution was washed with the aq $\mathrm{NaHCO}_{3}(5 \mathrm{~mL})$. The solvent was evaporated from the combined EtOAc layer and the residue was purified by column chromatography, eluting with hexane-EtOAc 8:2 to get the dichloro compound $11(0.040 \mathrm{~g})$ in $74 \%$ yield: $\mathrm{mp} 195-197^{\circ} \mathrm{C}$. IR $(\mathrm{KBr}) 3376,2944$, 1728, 1718, 1612, 1246, 1230, 790, $733 \mathrm{~cm}^{-1} ;{ }^{1} \mathrm{H} \mathrm{NMR}\left(\mathrm{CDCl}_{3}, 300 \mathrm{MHz}\right) \delta 8.91(\mathrm{~s}, 1 \mathrm{H})$, 
8.13 (s, $1 \mathrm{H}), 7.71$ (s, $1 \mathrm{H}), 7.42-7.37$ (m, $5 \mathrm{H}), 5.26$ (s, $2 \mathrm{H}), 4.05$ (s, $3 \mathrm{H}), 4.01(\mathrm{~s}, 3 \mathrm{H}) ;{ }^{13} \mathrm{C}$ NMR $\left(\mathrm{CDCl}_{3}, 75 \mathrm{MHz}\right) \delta 165.9,165.3,148.5,147.6,140.1,130.2,130.0,117.4,116.3$, 113.5, 51.5; ESIMS $\left(\mathrm{m} / z\right.$, relative intensity) $463\left(\mathrm{MH}^{+}, 100\right), 465\left(\mathrm{MH}^{+}, 65\right.$, chlorine isotope); HRMS calcd for $\mathrm{C}_{13} \mathrm{H}_{10} \mathrm{Cl}_{2} \mathrm{~N}_{2} \mathrm{O}_{4} 329.0096$, found 329.0093 .

\section{Methyl 7-amino-2-carbamoyl-5-chloroquinoline-4-carboxylate (12)}

The general procedure above for carboxamide synthesis was followed: $\mathrm{mp} 225-227{ }^{\circ} \mathrm{C}$. IR (KBr) 3356, 2961, 1726, 1713, 1633, 1247, 1242, 756, 725, $631 \mathrm{~cm}^{-1} ;{ }^{1} \mathrm{H} \mathrm{NMR}\left(\mathrm{CDCl}_{3}\right.$, $300 \mathrm{MHz}) \delta 7.95(\mathrm{~s}, 1 \mathrm{H}), 7.23(\mathrm{~d}, J=2.1 \mathrm{~Hz}, 1 \mathrm{H}), 7.18(\mathrm{~d}, J=2.1 \mathrm{~Hz}, 1 \mathrm{H}), 4.30(\mathrm{br} \mathrm{s}, 2$ $\mathrm{H}), 3.94(\mathrm{~s}, 3 \mathrm{H}) ;{ }^{13} \mathrm{C}$ NMR (DMSO- $\left.d_{6}, 125 \mathrm{MHz}\right) \delta 168.5,165.3,150.7,150.4,149.8$, 139.0, 128.5, 121.9, 113.3, 113.0, 106.8, 79.1, 59.7, 53.0; ESIMS ( $\mathrm{m} / z$, relative intensity) $280\left(\mathrm{MH}^{+}, 35\right), 282\left[\left(\mathrm{MH}^{+}, 14\right.\right.$, chlorine isotope)], 414 (33), 602 (100); HRMS calcd for $\mathrm{C}_{12} \mathrm{H}_{10} \mathrm{ClN}_{3} \mathrm{O}_{3} 279.0411$, found 279.0421 .

\section{Dimethyl 7-Acetamido-5-chloroquinoline-2,4-dicarboxylate (13)}

Amine $10(0.050 \mathrm{~g}, 0.17 \mathrm{mmol})$ was dissolved in anhydrous $\mathrm{CH}_{2} \mathrm{Cl}_{2}(4 \mathrm{~mL})$, and then DMAP $(0.062 \mathrm{~g}, 0.51 \mathrm{mmol})$ followed by $\mathrm{Ac}_{2} \mathrm{O}(0.034 \mathrm{~g}, 0.34 \mathrm{mmol})$ were added at room temperature and reaction mixture stirred at the same temperature for $2 \mathrm{~h}$. The mixture was neutralized with saturated aq $\mathrm{NH}_{4} \mathrm{Cl}$, dichloromethane $(30 \mathrm{~mL})$ was added, and the solution was washed with water $(2 \times 30 \mathrm{~mL})$. The combined organic layer was dried over $\mathrm{Na}_{2} \mathrm{SO}_{4}$ and then concentrated and purified by column chromatography (EtOAc-hexane 7:3) to get the product 13 as white solid $(0.045 \mathrm{~g})$ in $90 \%$ yield: $\mathrm{mp} 233-235^{\circ} \mathrm{C}$. IR $(\mathrm{KBr}) 2867,1746$, $1723,1678,1106,845,716,548 \mathrm{~cm}^{-1} ;{ }^{1} \mathrm{H}$ NMR $\left(\mathrm{CDCl}_{3}, 300 \mathrm{MHz}\right) \delta 8.31(\mathrm{~s}, 1 \mathrm{H}), 8.11(\mathrm{~s}$, $1 \mathrm{H}), 8.07(\mathrm{~s}, 1 \mathrm{H}) 4.04(\mathrm{~s}, 3 \mathrm{H}), 4.01(\mathrm{~s}, 3 \mathrm{H}), 2.19(\mathrm{~s}, 3 \mathrm{H}) ;{ }^{13} \mathrm{C} \mathrm{NMR}\left(\mathrm{CDCl}_{3}, 75 \mathrm{MHz}\right) \delta$ 168.2, 164.9, 164.5, 146.9, 146.2, 140.9, 132.3, 130.7, 118.3, 117.8, 111.4, 52.1, 24.8; ESIMS ( $\mathrm{m} / \mathrm{z}$, relative intensity) $337\left(\mathrm{MH}^{+}, 54\right), 339\left(\mathrm{MH}^{+}, 18\right.$, chlorine isotope), 295 (16), 376 (21); HRMS calcd for $\mathrm{C}_{15} \mathrm{H}_{13} \mathrm{ClN}_{2} \mathrm{O}_{5} 336.0513$, found 336.0511 .

\section{Methyl 7-Acetamido-2-carbamoyl-5-chloroquinoline-4-carboxylate (14)}

The general procedure above for carboxamide synthesis was followed: $\mathrm{mp} 240-242{ }^{\circ} \mathrm{C}$. IR (KBr) 2956, 1745, 1729, 1646, 1243, 843, 789, $569 \mathrm{~cm}^{-1} ;{ }^{1} \mathrm{H}$ NMR $\left(\mathrm{CDCl}_{3}, 300 \mathrm{MHz}\right) \delta$ 9.85 (s, $1 \mathrm{H}), 8.32$ (s, $1 \mathrm{H}), 7.90$ (s, $1 \mathrm{H}), 7.79$ (br s, $1 \mathrm{H}), 6.65$ (br s, $1 \mathrm{H}), 3.78$ (s, $3 \mathrm{H}), 2.02$ $(\mathrm{s}, 3 \mathrm{H}) ;{ }^{13} \mathrm{C}$ NMR $\left(\mathrm{CD}^{3} \mathrm{OD}, 125 \mathrm{MHz}\right) \delta 170.6,168.5,166.3,150.2,148.7,140.3,139.7$, 129.1, 118.7, 52.3, 22.5; ESIMS ( $/ 2 / z$, relative intensity) $322\left(\mathrm{MH}^{+}, 100\right), 324\left(\mathrm{MH}^{+}, 31\right.$, chlorine isotope); HRMS calcd for $\mathrm{C}_{14} \mathrm{H}_{12} \mathrm{ClN}_{3} \mathrm{O}_{4} 322.0594$, found 322.0596 .

\section{Dimethyl 5-Chloro-7-(dimethylamino)quinoline-2,4-dicarboxylate (15)}

Amine 10 (0.050 g, $0.170 \mathrm{mmol}$ ) was dissolved in anhydrous DMF $(4 \mathrm{~mL})$, and then $\mathrm{NaH}$ $(0.014 \mathrm{~g}, 0.510 \mathrm{mmol})$ followed by MeI $(0.160 \mathrm{~g}, 1.10 \mathrm{mmol})$ were added at room temperature and reaction mixture stirred at the same temperature for $1 \mathrm{~h}$. The reaction mixture quenched with saturated aq $\mathrm{NH}_{4} \mathrm{Cl}$, ethyl acetate $(30 \mathrm{~mL})$ was added, and the solution was washed with water $(2 \times 30 \mathrm{~mL})$. The combined organic layer was dried over $\mathrm{Na}_{2} \mathrm{SO}_{4}$ and then concentrated and purified by column chromatography (EtOAc-hexane 1:1) to get the product 15 as yellowish solid $(0.040 \mathrm{~g})$ in $80 \%$ yield: mp $155-157^{\circ} \mathrm{C}$. IR $(\mathrm{KBr})$ $2864,1734,1704,1023,844,734,678,546 \mathrm{~cm}^{-1} ;{ }^{1} \mathrm{H} \mathrm{NMR}\left(\mathrm{CDCl}_{3}, 300 \mathrm{MHz}\right) \delta 7.84(\mathrm{~s}, 1$ H), $7.33(\mathrm{~d}, J=2.7 \mathrm{~Hz}, 1 \mathrm{H}), 7.26(\mathrm{~d}, J=2.7 \mathrm{~Hz}, 1 \mathrm{H}), 4.03(\mathrm{~s}, 3 \mathrm{H}), 3.98(\mathrm{~s}, 3 \mathrm{H}), 3.09$ (s, 6 $\mathrm{H}) ;{ }^{13} \mathrm{C} \mathrm{NMR}\left(\mathrm{CDCl}_{3}, 75 \mathrm{MHz}\right) \delta 163.4,162.8,145.8,145.7,140.3,131.8,129.9,117.4$, 116.6, 111.8, 52.6, 41.8; ESIMS ( $/ 2 / z$, relative intensity) $323\left(\mathrm{MH}^{+}, 100\right), 325\left(\mathrm{MH}^{+}, 31\right.$, chlorine isotope), 263 (19), 324 (16); HRMS calcd for $\mathrm{C}_{15} \mathrm{H}_{15} \mathrm{ClN}_{2} \mathrm{O}_{4} 323.0799$, found 323.0803 . 


\section{Methyl 2-Carbamoyl-5-chloro-7-(dimethylamino)quinoline-4-carboxylate (16)}

Compound 15 was dissolved in THF $(6 \mathrm{~mL})$ and a $30 \% \mathrm{NH}_{4} \mathrm{OH}$ solution $(2 \mathrm{~mL})$ was added. The reaction mixture stirred at room temperature for $24 \mathrm{~h}$, by which time all of the ester had been converted to amide. THF was removed on a rotary evaporator, $\mathrm{CHCl} 3(20 \mathrm{~mL})$ was added, and the mixture was washed with water $(2 \times 15 \mathrm{~mL})$. The combined organic layer was dried over $\mathrm{Na}_{2} \mathrm{SO}_{4}$, and then concentrated to get the amide $16(0.020 \mathrm{~g})$ in quantitative yield as yellowish solid: $\mathrm{mp} 260-262{ }^{\circ} \mathrm{C}$. IR ( $\left.\mathrm{KBr}\right) 3416,3186,1737,1687,1612,1212$, 1116, 761, $658 \mathrm{~cm}^{-1} ;{ }^{1} \mathrm{H}$ NMR $\left(\mathrm{CDCl}_{3}, 300 \mathrm{MHz}\right) \delta 7.94(\mathrm{~s}, 1 \mathrm{H}), 7.92(\mathrm{brs}, 1 \mathrm{H}), 7.31(\mathrm{~d}, J$ $=2.7 \mathrm{~Hz}, 1 \mathrm{H}), 7.07(\mathrm{~d}, J=2.7 \mathrm{~Hz}, 1 \mathrm{H}), 5.48(\mathrm{brs}, 1 \mathrm{H}), 3.98(\mathrm{~s}, 3 \mathrm{H}), 3.11(\mathrm{~s}, 6 \mathrm{H}) ;{ }^{13} \mathrm{C}$ NMR $\left(\mathrm{CD}_{3} \mathrm{OD}, 125 \mathrm{MHz}\right) \delta 170.7,163.3,152.4,151.2,141.1,130.9,120.9,114.7,107.6$, 105.9, 53.6, 40.2; ESIMS ( $\mathrm{m} / z$, relative intensity) $308\left(\mathrm{MH}^{+}, 100\right), 310\left(\mathrm{MH}^{+}, 27\right.$, chlorine isotope), 248 (22), 303 (29); HRMS calcd for $\mathrm{C}_{14} \mathrm{H}_{14} \mathrm{ClN}_{3} \mathrm{O}_{3} 308.0802$, found 308.0803 .

\section{Dimethyl 7-Amino-6-iodoquinoline-2,4-dicarboxylate (18)}

A solution of $(E)$-dimethyl 4-oxopent-2-enedioate $(0.80 \mathrm{~g}, 4.8 \mathrm{mmol})$ in dichloromethane $(30 \mathrm{~mL})$ was added to a solution of 4,6-diiodobenzene-1,3-diamine $\mathbf{1 7}(1.0 \mathrm{~g}, 2.7 \mathrm{mmol})$ in dichloromethane $(10 \mathrm{~mL})$ and the reaction mixture stirred for $30 \mathrm{~min}$. A catalytic amount of PTSA $(0.180 \mathrm{~g}, 0.949 \mathrm{mmol})$ and $\mathrm{Cu}(\mathrm{OAc})_{2}(0.116 \mathrm{~g}, 0.632 \mathrm{mmol})$ was added and the solution was heated at reflux for $24 \mathrm{~h}$. The reaction mixture was washed 3 times with $\mathrm{NaHCO}_{3}(15 \mathrm{~mL})$. The organic layer was separated and dried over $\mathrm{Na}_{2} \mathrm{SO}_{4}$ and purified by silica gel column chromatography using hexane- EtOAc 7:3 to get the product $18(0.30 \mathrm{mg})$ in 30\% yield: $\mathrm{mp} 133-135^{\circ} \mathrm{C}$. IR (KBr) $3364,2943,1728,1712,1643,1255,1221,791$, $723,631 \mathrm{~cm}^{-1} ;{ }^{1} \mathrm{H} \mathrm{NMR}\left(\mathrm{CDCl}_{3}, 300 \mathrm{MHz}\right) \delta 9.30(\mathrm{~s}, 1 \mathrm{H}), 8.37(\mathrm{~s}, 1 \mathrm{H}), 7.46(\mathrm{~s}, 1 \mathrm{H}), 4.04$ $(\mathrm{s}, 3 \mathrm{H}), 4.01(\mathrm{~s}, 3 \mathrm{H}) ;{ }^{13} \mathrm{C} \mathrm{NMR}\left(\mathrm{CDCl}_{3}, 75 \mathrm{MHz}\right) \delta 166.2,165.8,149.2,148.3,147.9$, 134.0, 133.1, 115.1, 87.1, 50.8; ESIMS ( $\mathrm{m} / 2$, relative intensity) $387\left(\mathrm{MH}^{+}, 100\right)$; HRMS calcd for $\mathrm{C}_{14} \mathrm{H}_{11} \mathrm{IN}_{2} \mathrm{O}_{4} 386.1405$, found 386.1409 .

\section{7-Amino-6-iodoquinoline-2,4-dicarboxamide (19) and 7-Amino-6-iodo-4- methoxycarbonylquinoline-2-carboxamide (20)}

Compound $\mathbf{1 8}$ was dissolved in THF $(6 \mathrm{~mL})$ and a $30 \% \mathrm{NH}_{4} \mathrm{OH}$ solution $(2 \mathrm{~mL})$ was added. The reaction mixture stirred at $70{ }^{\circ} \mathrm{C}$ for $24 \mathrm{~h}$ in a seal tube. THF was removed on a rotary evaporator, $\mathrm{CHCl}_{3}(20 \mathrm{~mL})$ was added, and the mixture was washed with water $(2 \times 15$ $\mathrm{mL}$ ). The combined organic layer was dried over $\mathrm{Na}_{2} \mathrm{SO}_{4}$, and then concentrated and purified by silica gel column chromatography using hexane- EtOAc 4:6 to get the diamide product $19(0.020 \mathrm{~g})$ in $20 \%$ yield along with monoamide $20(0.040)$ in $40 \%$ yield: $19 \mathrm{mp}$ $195-197{ }^{\circ} \mathrm{C}$. IR (KBr) 3416, 3186, 1737, 1687, 1612, 1212, 1116, 761, $658 \mathrm{~cm}^{-1} ;{ }^{1} \mathrm{H}$ NMR (DMSO-d $\left.d_{6}, 500 \mathrm{MHz}\right) \delta 8.61$ (s, $\left.1 \mathrm{H}\right), 8.28$ (br s, $\left.1 \mathrm{H}\right), 8.19$ (br s, $\left.1 \mathrm{H}\right), 7.84$ (br s, $\left.1 \mathrm{H}\right), 7.76$ (s, $1 \mathrm{H}), 7.73$ (br s, $1 \mathrm{H}), 7.26(\mathrm{~s}, 1 \mathrm{H}), 6.03(\mathrm{~s}, 2 \mathrm{H}) ;{ }^{13} \mathrm{C}$ NMR (DMSO- $\left.d_{6}, 125 \mathrm{MHz}\right) \delta$ 168.4, 166.0, 150.5, 149.9, 148.4, 141.4, 135.9, 118.5, 112.2, 107.2, 92.4; ESIMS ( $\mathrm{m} / z$, relative intensity) $357\left(\mathrm{MH}^{+}, 100\right)$; HRESIMS calcd for $\mathrm{C}_{11} \mathrm{H}_{9} \mathrm{IN}_{4} \mathrm{O}_{2} 355.9770$, found 355.9774. 20: $\mathrm{mp} 164-166^{\circ} \mathrm{C}$. IR (KBr): $3583,3318,1724,1673,1612,1490,1313,1231$, 1196, 1174, $726 \mathrm{~cm}^{-1} ;{ }^{1} \mathrm{H}$ NMR $\left(\mathrm{CDCl}_{3}, 300 \mathrm{MHz}\right) \delta 9.31(\mathrm{~s}, 1 \mathrm{H}), 8.49$ (s, $\left.1 \mathrm{H}\right), 7.30$ (s, 2 H), 4.63 (br s, $2 \mathrm{H}$ ), 3.99 (s, $3 \mathrm{H}$ ); ${ }^{13} \mathrm{C}$ NMR (DMSO- $d_{6}, 125 \mathrm{MHz}$ ) 165.7, 165.6, 150.4, $149.9,148.8,135.6,133.6,118.4,115.2,107.2,93.5,52.8$; ESIMS ( $\mathrm{m} / z$, relative intensity) $372\left(\mathrm{MH}^{+}, 100\right)$; HRMS calcd for $\mathrm{C}_{12} \mathrm{H}_{10} \mathrm{IN}_{3} \mathrm{O}_{3} 371.9845$, found 371.9851 .

\section{Dimethyl 6,7-Diamino-5-chloroquinoline-2,4-dicarboxylate (22)}

A solution of $(E)$-dimethyl 4-oxopent-2-enedioate $(1.30 \mathrm{~g}, 7.59 \mathrm{mmol})$ in dichloromethane $(30 \mathrm{~mL})$ was added to a solution of triamine $21(1.0 \mathrm{~g}, 4.1 \mathrm{mmol})$ in dichloromethane (10 $\mathrm{mL})$ and the reaction mixture stirred for $30 \mathrm{~min}$. A catalytic amount of PTSA $(0.180 \mathrm{~g}$, $0.949 \mathrm{mmol})$ and $\mathrm{Cu}(\mathrm{OAc})_{2}(0.116 \mathrm{~g}, 0.632 \mathrm{mmol})$ was added and the solution was heated at 
reflux for $24 \mathrm{~h}$. The reaction mixture was washed 3 times with $\mathrm{NaHCO}_{3}(15 \mathrm{~mL})$. The organic layer was separated and dried over $\mathrm{Na}_{2} \mathrm{SO}_{4}$ and purified by silica gel column chromatography using hexane-EtOAc 1:9 to get the product $22(0.5 \mathrm{mg})$ in $25 \%$ yield: $\mathrm{mp}$ 203-205 ${ }^{\circ} \mathrm{C} .{ }^{1} \mathrm{H}$ NMR $\left(\mathrm{CDCl}_{3}, 300 \mathrm{MHz}\right) \delta 7.96$ (s, $\left.1 \mathrm{H}\right), 7.44$ (s, $\left.1 \mathrm{H}\right), 4.60$ (br. s $\left.1 \mathrm{H}\right), 4.00$ $(\mathrm{s}, 3 \mathrm{H}), 3.98(\mathrm{~s}, 3 \mathrm{H}){ }^{13} \mathrm{C} \mathrm{NMR}\left(\mathrm{CDCl}_{3}, 75 \mathrm{MHz}\right) \delta 169.2,165.0,144.3,142.2,139.4$, 147.6, 118.6, 112.6, 55.0; ESIMS ( $\mathrm{m} / z$, relative intensity) $\left.310\left(\mathrm{MH}^{+}, 100\right)\right], 312\left(\mathrm{MH}^{+}, 35\right.$, chlorine isotope); HRMS calcd for $\mathrm{C}_{13} \mathrm{H}_{12} \mathrm{ClN}_{3} \mathrm{O}_{4} 310.0598$, found 310.0598 .

\section{Methyl 6,7-Diamino-2-carbamoyl-5-chloroquinoline-4-carboxylate (23)}

The general procedure above for carboxamide synthesis was followed: $\mathrm{mp} 280-282{ }^{\circ} \mathrm{C} ;{ }^{1} \mathrm{H}$ NMR $\left(\mathrm{CDCl}_{3}, 300 \mathrm{MHz}\right) \delta 8.08$ (s, $\left.1 \mathrm{H}\right), 7.88$ (br. s, $\left.1 \mathrm{H}\right), 7.26$ (s, $1 \mathrm{H}$ ), 5.66 (br. s, $1 \mathrm{H}$ ), 4.53 (br s, $4 \mathrm{H}$ ), 4.00 (s, $3 \mathrm{H}$ ); ${ }^{13} \mathrm{C}$ NMR (DMSO- $\left.d_{6}, 125 \mathrm{MHz}\right) \delta 169.6,165.9,144.6$, 142.9, 141.1, 137.0, 134.7, 116.2, 113.6, 106.5, 104.7, 52.6; ESIMS ( $\mathrm{m} / \mathrm{z}$, relative intensity) $295\left(\mathrm{MH}^{+}, 100\right), 297\left(\mathrm{MH}^{+}, 30\right.$, chlorine isotope $), 317\left[\left(\mathrm{MNa}^{+}, 17\right)\right], 319\left(\mathrm{MNa}^{+}, 5\right.$, chlorine isotope); HRMS calcd for $\mathrm{C}_{12} \mathrm{H}_{11} \mathrm{ClN}_{4} \mathrm{O}_{3} \mathrm{Na}$ 317.0417, found 317.0420.

\section{Dimethyl 5-Amino-6,8-dichloro-4-hydroxy-1,2,3,4-tetrahydroquinoline-2,4-dicarboxylate} (26)

A solution of (E)-dimethyl 4-oxopent-2-enedioate (5) $(1.70 \mathrm{~g}, 6.25 \mathrm{mmol})$ in dichloromethane $(30 \mathrm{~mL})$ was added to a solution of diamine $(1.0 \mathrm{~g}, 5.26 \mathrm{mmol})$ in dichloromethane $(10 \mathrm{~mL})$ and the reaction mixture stirred for $30 \mathrm{~min}$. A catalytic amount of PTSA $(0.180 \mathrm{~g}, 0.66 \mathrm{mmol})$ and $0.2 \mathrm{eq}$. of $\mathrm{Cu}(\mathrm{OAc})_{2}$ were added and the solution was heated at reflux for $24 \mathrm{~h}$. The reaction mixture was washed 3 times with $\mathrm{NaHCO}_{3}(15 \mathrm{~mL})$. The organic layer was separated and dried over $\mathrm{Na}_{2} \mathrm{SO}_{4}$ and purified by silica gel column chromatography using hexane-EtOAc $9: 1$ to get the product $26(0.650 \mathrm{mg})$ in $65 \%$ yield. $\mathrm{mp}$ $170-172{ }^{\circ} \mathrm{C}$. IR (KBr) 3476, 2952, 1743, 1022, 879, 743, $546 \mathrm{~cm}^{-1} ;{ }^{1} \mathrm{H} \mathrm{NMR}\left(\mathrm{CDCl}_{3}, 300\right.$ MHz) $\delta 7.18$ (s, $1 \mathrm{H}), 5.23$ (brs, $1 \mathrm{H}), 4.21$ (brs, $2 \mathrm{H}), 4.00(\mathrm{~d}, J=12 \mathrm{~Hz}, 1 \mathrm{H}), 3.81(\mathrm{~s}, 3 \mathrm{H})$, $3.71(\mathrm{~s}, 3 \mathrm{H}), 2.30(\mathrm{~d}, J=10 \mathrm{~Hz}, 1 \mathrm{H}), 2.13(\mathrm{dd}, J=4.5,10 \mathrm{~Hz}, 1 \mathrm{H}) ;{ }^{13} \mathrm{C}$ NMR (DMSO- $d_{6}$, $125 \mathrm{MHz}) \delta 175.2$, 171.6, 142.3, 139.4, 128.0, 109.5, 106.9, 106.6, 79.1, 71.6, 52.5, 52.2, 49.7; EIMS $\left(m / z\right.$, relative intensity) $348\left(\mathrm{MH}^{+}, 100\right)$; HRMS calcd for $\mathrm{C}_{13} \mathrm{H}_{14} \mathrm{Cl}_{2} \mathrm{~N}_{2} \mathrm{O}_{5}$ 348.0280 , found 348.0283 .

\section{Dimethyl 5-Amino-6,8-dichloroquinoline-2,4-dicarboxylate (27)}

Compound $26(0.9 \mathrm{~g}, 2.5 \mathrm{mmol})$ was dissolved in thionyl chloride $(8 \mathrm{~mL})$ and then the reaction mixture was heated at $90^{\circ} \mathrm{C}$ for $3 \mathrm{~h}$, after which thionyl chloride was removed on a rotary evaporator, ethyl acetate $(60 \mathrm{~mL})$ was added, and the solution washed with saturated aq. $\mathrm{NaHCO}_{3}(2 \times 30 \mathrm{~mL})$. The combined organic layer was dried over $\mathrm{Na}_{2} \mathrm{SO}_{4}$ and then concentrated to get the product 27 as reddish solid $(0.810 \mathrm{~g})$ in $95 \%$ yield: $\mathrm{mp} 313-315^{\circ} \mathrm{C}$. IR (KBr) 3420, 2924, 1740, 1204, 845, $622 \mathrm{~cm}^{-1} ;{ }^{1} \mathrm{H}$ NMR $\left(\mathrm{CDCl}_{3}, 300 \mathrm{MHz}\right) \delta 8.19$ (s, 1 H), $7.85(\mathrm{~s}, 1 \mathrm{H}), 4.03(\mathrm{~s}, 3 \mathrm{H}), 4.02(\mathrm{~s}, 3 \mathrm{H})$; ESIMS $\left(\mathrm{m} / z\right.$, relative intensity) $351\left(\mathrm{MNa}^{+}\right.$, 100), $353\left(\mathrm{MNa}^{+}, 59\right.$, chlorine isotope), 253 (73), 255 (53); HRMS calcd for $\mathrm{C}_{13} \mathrm{H}_{10} \mathrm{Cl}_{2} \mathrm{~N}_{2} \mathrm{O}_{4} \mathrm{Na} 350.9915$, found 350.9917 .

\section{Methyl 6,8-Dichloro-2-oxo-1,2-dihydropyrrolo[4,3,2-d,e]quinoline-4-carboxylate (28)}

Compound $27(0.810 \mathrm{~g}, 2.39 \mathrm{mmol})$ was dissolved in dichloromethane $(25 \mathrm{~mL})$ and excess $\mathrm{Et}_{3} \mathrm{~N}(2 \mathrm{~mL})$ was added. The reaction mixture kept aside for $24 \mathrm{~h}$ at room temperature, by which time undissolved solid was formed. The solid was filtered off and dried to get product 28 as dark yellowish solid $(0.621 \mathrm{~g})$ in $85 \%$ yield and used the crude product as such for the next reaction: $\mathrm{mp}>300^{\circ} \mathrm{C}$. $\mathrm{IR}(\mathrm{KBr}): 3177,2348,1717,1635,1449,1349,1279,1227$, $1163,1123,1073,1051,740,670,524 \mathrm{~cm}^{-1} ;{ }^{1} \mathrm{H}$ NMR (DMSO- $\left.d_{6}, 300 \mathrm{MHz}\right) \delta 11.84(\mathrm{~s}, 1$ H), 8.44 (s, $1 \mathrm{H}), 7.99$ (s, $1 \mathrm{H}), 4.00(\mathrm{~s}, 3 \mathrm{H}) ;{ }^{13} \mathrm{C}$ NMR (DMSO-d 6 , $\left.125 \mathrm{MHz}\right) 168.4,164.7$, 
158.8, 158.5, 158.2, 157.9, 118.5, 116.2, 113.9, 11.6; EIMS ( $\mathrm{m} / \mathrm{z}$, relative intensity) 296

$\left(\mathrm{MH}^{+}, 100\right)$; HRMS calcd for $\mathrm{C}_{12} \mathrm{H}_{6} \mathrm{Cl}_{2} \mathrm{~N}_{2} \mathrm{O}_{3} 295.9755$, found 295.9759 .

\section{Methyl 6,8-Dichloro-1-methyl-2-oxo-1,2-dihydropyrrolo[4,3,2-d,e]quinoline-4-carboxylate (29)}

A solution of $28(0.621 \mathrm{~g}, 2.09 \mathrm{mmol})$ in DMF $(20 \mathrm{~mL})$ was heated to $90{ }^{\circ} \mathrm{C}$ and then $\mathrm{NaH}$ $(0.160 \mathrm{~g}, 4.1 \mathrm{mmol})$ followed $\mathrm{CH}_{3} \mathrm{I}(2.8 \mathrm{~g}, 20.9 \mathrm{mmol})$ were added. After addition of $\mathrm{CH}_{3} \mathrm{I}$, solid came out from solution. Reaction was continued for $1 \mathrm{~h}$ and then the solid was filtered off and washed with water and dried to get compound $29(0.600 \mathrm{~g})$ in $92 \%$ yield as yellowish solid: $\mathrm{mp} 278-280^{\circ} \mathrm{C}$. IR (KBr) 2924, 2854, 1718, 1448, 1205, 1025, 736, 574 $\mathrm{cm}^{-1} ;{ }^{1} \mathrm{H} \mathrm{NMR}\left(\mathrm{CDCl}_{3}, 300 \mathrm{MHz}\right) \delta 8.71(\mathrm{~s}, 1 \mathrm{H}), 7.66(\mathrm{~s}, 1 \mathrm{H}), 4.09(\mathrm{~s}, 3 \mathrm{H}), 3.68(\mathrm{~s}, 3 \mathrm{H})$; $\operatorname{EIMS}\left(\mathrm{m} / z\right.$, relative intensity) $311\left(\mathrm{MH}^{+}, 100\right), 313\left(\mathrm{MH}^{+}, 59\right.$, chlorine isotope $\left.)\right]$; HRMS calcd for $\mathrm{C}_{13} \mathrm{H}_{8} \mathrm{Cl}_{2} \mathrm{~N}_{2} \mathrm{O}_{3} 309.9824$, found 309.9909 .

\section{6,8-Dichloro-1-Methyl-2-oxo-1,2-dihydropyrrolo[4,3,2-d,e]quinoline-4-carboxamide (30)}

Compound 29 was dissolved in THF $(250 \mathrm{~mL})$ and a $30 \% \mathrm{NH}_{4} \mathrm{OH}$ solution $(20 \mathrm{~mL})$ was added. The reaction mixture stirred at room temperature for $24 \mathrm{~h}$, by which time all of the ester had been converted to amide. THF was removed on a rotary evaporator, $\mathrm{CHCl}_{3}(150$ $\mathrm{mL}$ ) was added, and the mixture was washed with water $(2 \times 40 \mathrm{~mL})$. The combined organic layer was dried over $\mathrm{Na}_{2} \mathrm{SO}_{4}$, and then concentrated to get the amide $\mathbf{3 0}(0.580 \mathrm{~g})$ in quantitative yield as yellowish solid: $\mathrm{mp} 288-290^{\circ} \mathrm{C}$. IR (KBr) $3452,3184,1716,1245$, 1024, 810, 651, $574 \mathrm{~cm}^{-1} ;{ }^{1} \mathrm{H}$ NMR (DMSO- $\left.d_{6}, 300 \mathrm{MHz}\right) \delta 8.48(\mathrm{~s}, 1 \mathrm{H}), 8.17(\mathrm{~s}, 1 \mathrm{H})$, $8.09(\mathrm{~s}, 1 \mathrm{H}), 7.98(\mathrm{~s}, 1 \mathrm{H}), 3.55(\mathrm{~s}, 3 \mathrm{H})$; EI-CIMS $\left(\mathrm{m} / z\right.$, relative intensity) $296\left(\mathrm{MH}^{+}, 100\right)$, $298\left(\mathrm{MH}^{+}, 62\right.$, chlorine isotope); HRMS calcd for $\mathrm{C}_{12} \mathrm{H}_{7} \mathrm{Cl}_{2} \mathrm{~N}_{3} \mathrm{O}_{2} 294.9915$, found 294.9919.

\section{N-Benzyl-6,8-Dichloro-1-methyl-2-oxo-1,2-dihydropyrrolo[4,3,2-d,e]quinoline-4- carboxamide (31)}

Compound 30 (0.050 g, $0.168 \mathrm{mmol})$ was dissolved in anhydrous THF $(4 \mathrm{~mL})$, and then $\operatorname{BuLi}(1.0 \mathrm{~mL}, 0.337 \mathrm{mmol})$ followed by $\operatorname{BnBr}(0.034 \mathrm{~g}, 0.202 \mathrm{mmol})$ were added at $-78^{\circ} \mathrm{C}$ and the reaction mixture stirred at the same temperature for $3 \mathrm{~h}$. The reaction was quenched with saturated aq $\mathrm{NH}_{4} \mathrm{Cl}$, ethyl acetate $(30 \mathrm{~mL})$ was added, and the solution was washed with water $(2 \times 30 \mathrm{~mL})$. The combined organic layer was dried over $\mathrm{Na}_{2} \mathrm{SO}_{4}$ and then concentrated and purified by column chromatography (EtOAc-hexane 5:5) to afford the product 31 as yellowish solid $(0.030 \mathrm{~g})$ in $65 \%$ yield: $\mathrm{mp} 236-238^{\circ} \mathrm{C}$. IR $(\mathrm{KBr}) 3397,1718$, $1678,1529,1519,1244,1023,575 \mathrm{~cm}^{-1} ;{ }^{1} \mathrm{H} \mathrm{NMR}\left(\mathrm{CDCl}_{3}, 300 \mathrm{MHz}\right) \delta 8.88(\mathrm{~s}, 1 \mathrm{H}), 8.62$ (br s, $1 \mathrm{H}), 7.69(\mathrm{~s}, 1 \mathrm{H}), 7.61-7.28(\mathrm{~m}, 5 \mathrm{H}) 4.75(\mathrm{~d}, \mathrm{~J}=6.3 \mathrm{~Hz}, 2 \mathrm{H}), 3.68(\mathrm{~s}, 3 \mathrm{H}) ;{ }^{13} \mathrm{C}$ NMR $\left(\mathrm{CDCl}_{3}, 125 \mathrm{MHz}\right) \delta 165.8,162.9,153.5,139.4,137.8,135.5,134.8,134.4,128.7$, 128.5, 128.0, 127.7, 127.6, 127.3, 122.7, 117.8, 113.6, 43.7, 28.5; ESIMS $(\mathrm{m} / \mathrm{z}$, relative intensity) $386\left(\mathrm{MH}^{+}, 100\right), 388\left(\mathrm{MH}^{+}, 60\right.$, chlorine isotope); HRMS calcd for $\mathrm{C}_{19} \mathrm{H}_{13} \mathrm{Cl}_{2} \mathrm{~N}_{3} \mathrm{O}_{2} 386.0463$, found 386.0470 .

\section{6,8-Dichloro-N,N,1-trimethyl-2-oxo-1,2-dihydropyrrolo[4,3,2-d,e]quinoline-4-carboxamide (32)}

Compound $30(0.050 \mathrm{~g}, 0.168 \mathrm{mmol})$ was dissolved in anhydrous DMF (4 mL), and then $\mathrm{NaH}(0.016 \mathrm{~g}, 0.675 \mathrm{mmol})$ followed by $\mathrm{MeI}(0.190 \mathrm{~g}, 1.34 \mathrm{mmol})$ were added at room temperature and the reaction mixture stirred at the same temperature for $1 \mathrm{~h}$. The reaction was quenched with saturated aq $\mathrm{NH}_{4} \mathrm{Cl}$, ethyl acetate $(30 \mathrm{~mL})$ was added, and the solution was washed with water $(2 \times 30 \mathrm{~mL})$. The combined organic layer was dried over $\mathrm{Na}_{2} \mathrm{SO}_{4}$ and then concentrated and purified by column chromatography (EtOAc-hexane 6:4) to get the product 32 as yellowish solid $(0.040 \mathrm{~g})$ in $85 \%$ yield: $\mathrm{mp} 236-238{ }^{\circ} \mathrm{C}$. IR (KBr) 2840 , 
1734, 1276, 1023, 865, 726, $547 \mathrm{~cm}^{-1} ;{ }^{1} \mathrm{H} \mathrm{NMR}\left(\mathrm{CDCl}_{3}, 300 \mathrm{MHz}\right) \delta 8.30(\mathrm{~s}, 1 \mathrm{H}), 7.62(\mathrm{~s}$, $1 \mathrm{H}), 3.67(\mathrm{~s}, 3 \mathrm{H}), 3.21(\mathrm{~s}, 6 \mathrm{H})$; ESIMS $\left(\mathrm{m} / z\right.$, relative intensity) $324\left(\mathrm{MH}^{+}, 60\right), 326\left(\mathrm{MH}^{+}\right.$, 38 , chlorine isotope), $346\left(\mathrm{MNa}^{+}, 13\right)$; HRMS calcd for $\mathrm{C} 14 \mathrm{H} 11 \mathrm{Cl} 2 \mathrm{~N} 3 \mathrm{O} 2324.0307$, found 324.0304 .

\section{Methyl 6,8-Dichloro-2a-hydroxy-2-oxo-1,2,2a,3,4,5-hexahydropyrrolo[4,3,2-d,e]quinoline-4- carboxylate (33)}

To a stirred solution of compound $26(0.5 \mathrm{~g}, 1.43 \mathrm{mmol})$ in anhydrous THF $(10 \mathrm{~mL})$ was added $\mathrm{NaH}(0.1 \mathrm{~g}, 2.15 \mathrm{mmol})$ at room temperature and reaction mixture stirred for another $15 \mathrm{~min}$. and then quenched with aq. $\mathrm{NH}_{4} \mathrm{Cl}(10 \mathrm{~mL})$ and then extracted with EtOAc $(2 \times 20$ $\mathrm{mL})$. The combined ethyl acetate solution was washed with water $(15 \mathrm{~mL})$ and brine $(15$ $\mathrm{mL}$ ) and the ethyl acetate was evaporated in the rotavapor to get the product $\mathbf{3 3}$ as white solid $\left(0.390 \mathrm{~g}\right.$ ) in $85 \%$ yield: mp $241-243{ }^{\circ} \mathrm{C} .{ }^{1} \mathrm{H}$ NMR (DMSO- $\left.d_{6}, 300 \mathrm{MHz}\right) \delta 10.59$ (s, 1 H), $7.20(\mathrm{~s}, 1 \mathrm{H}), 6.48(\mathrm{~s}, 1 \mathrm{H}), 5.94(\mathrm{~s}, 1 \mathrm{H}), 4.37(\mathrm{dd}, J=3.9,12.9 \mathrm{~Hz}, 1 \mathrm{H}), 3.71(\mathrm{~s}, 3 \mathrm{H})$, $2.32(\mathrm{dd}, J=3.9,12.9 \mathrm{~Hz}, 1 \mathrm{H}), 1.14(\mathrm{t}, J=12.9 \mathrm{~Hz}, 1 \mathrm{H})$; ESIMS $(\mathrm{m} / z$, relative intensity) $339\left(\mathrm{MNa}^{+}, 100\right), 341\left(\mathrm{MNa}^{+}, 62\right.$, chlorine isotope); HRMS calcd for $\mathrm{C}_{12} \mathrm{H}_{10} \mathrm{Cl}_{2} \mathrm{~N}_{2} \mathrm{O}_{4} \mathrm{Na}$ 338.9915, found 338.9912 .

\section{Methyl 6,8-Dichloro-1-methyl-7-nitro-2-oxo-1,2-dihydropyrrolo[4,3,2-d,e]quinoline-4- carboxylate (34)}

Compound $29(0.1 \mathrm{~g}, 0.322 \mathrm{mmol})$ was dissolved in a mixture of $\mathrm{HNO}_{3}$ and $\mathrm{H}_{2} \mathrm{SO}_{4}(3 \mathrm{~mL}$, $2: 1$ ) and then the reaction mixture was stirred at room temperature for $2 \mathrm{~h}$. The mixture of acids was neutralized with saturated aq $\mathrm{NaHCO}_{3}$, chloroform $(40 \mathrm{~mL})$ was added, and the solution was washed with water $(2 \times 30 \mathrm{~mL})$. The combined organic layer was dried over $\mathrm{Na}_{2} \mathrm{SO}_{4}$ and then concentrated to get the product 34 (structure confirmed by X-ray crystallography) as yellowish solid $(0.1 \mathrm{~g})$ in $87 \%$ yield: $\mathrm{mp} 223-225^{\circ} \mathrm{C}$. IR $(\mathrm{KBr}) 2955$, 2925, 1727, 1440, 1262, 1217, 1027, 740, $575 \mathrm{~cm}^{-1} ;{ }^{1} \mathrm{H} \mathrm{NMR}\left(\mathrm{CDCl}_{3}, 300 \mathrm{MHz}\right) \delta 8.77(\mathrm{~s}$, $1 \mathrm{H}), 4.09$ (s, $3 \mathrm{H}), 3.85$ (s, $3 \mathrm{H}) ;{ }^{13} \mathrm{C} \mathrm{NMR}\left(\mathrm{CDCl}_{3}, 75 \mathrm{MHz}\right) \delta 173.7,173.0,164.2,163.7$, $155.1,142.5,142.0,135.4,134.4,134.1,123.4,53.8,29.6$; ESIMS ( $\mathrm{m} / z$, relative intensity) $307\left(\mathrm{MH}^{+}, 100\right), 309\left(\mathrm{MH}^{+}, 65\right.$, chlorine isotope), $329\left(\mathrm{MNa}^{+}, 45\right), 331\left(\mathrm{MNa}^{+}, 30\right)$; HRMS calcd for $\mathrm{C}_{13} \mathrm{H}_{7} \mathrm{ClN}_{2} \mathrm{O}_{5} \mathrm{Na} 328.9941$, found 328.9944.

\section{8-Amino-7-chloro-1-methyl-6-(methylamino)-2-oxo-1,2-dihydropyrrolo[4,3,2- d,e]quinoline-4-carboxamide (38)}

$\mathrm{NaH}$ ( $15 \mathrm{mg}, 0.308 \mathrm{mmol}$ ) followed by $\mathrm{CH}_{3} \mathrm{I}(45 \mathrm{mg}, 0.308 \mathrm{mmol})$ were added to a stirred solution of $\mathbf{3 5}^{5}(0.075 \mathrm{~g}, 0.256 \mathrm{mmol})$ in DMF $(3 \mathrm{~mL})$. The mixture was stirred at room temperature for $1 \mathrm{~h}$, quenched with saturated aq $\mathrm{NH}_{4} \mathrm{Cl}$, and extracted with EtOAc $(4 \times 30$ $\mathrm{mL}$ ). The combined organic layer was dried over $\mathrm{Na}_{2} \mathrm{SO}_{4}$, concentrated, and purified by silica gel column chromatography using $\mathrm{CHCl}_{3}-\mathrm{MeOH}$ (9.4:0.6) to furnish major product $\mathbf{3 6}^{5}(0.056 \mathrm{~g}, 70 \%)$ and minor product $\mathbf{3 7}(0.012 \mathrm{~g}, 15 \%)$ as a purple solids. Compound $\mathbf{3 7}$ $(0.012 \mathrm{~g}, 0.037 \mathrm{mmol})$ was dissolved in THF $(8 \mathrm{~mL})$ and a $30 \% \mathrm{NH}_{4} \mathrm{OH}$ solution $(0.5 \mathrm{~mL})$ was added. The reaction mixture stirred at room temperature for $24 \mathrm{~h}$. The THF was removed on a rotary evaporator and the product was purified by silica gel column chromatography using $\mathrm{CHCl}_{3}-\mathrm{MeOH}(9.0: 1.0)$ to yield the product $\mathbf{3 8}(0.08 \mathrm{~g}, 80 \%)$ as a purple solid: $\mathrm{mp}>300{ }^{\circ} \mathrm{C}$. IR (KBr) 3357, 3168, 2941, 2835, 1671, 1378, 1154, 595, 473 $\mathrm{cm}^{-1} ;{ }^{1} \mathrm{H} \mathrm{NMR}\left(\mathrm{CDCl}_{3}, 300 \mathrm{MHz}\right) \delta 8.68(\mathrm{~s}, 1 \mathrm{H}), 8.10$ (br s, $\left.1 \mathrm{H}\right), 5.97$ (br s $\left.1 \mathrm{H}\right), 5.23$ (br s $2 \mathrm{H}), 3.54$ (s, $3 \mathrm{H}), 2.85$ (s, $3 \mathrm{H}$ ); ${ }^{13} \mathrm{C}$ NMR (DMSO- $\left.d_{6}, 125 \mathrm{MHz}\right) \delta 165.9,165.5,146.5$, 140.1, 135.1, 132.0, 131.9, 120.1, 115.0, 112.6, 108.6, 37.0, 30.3; ESIMS $(\mathrm{m} / \mathrm{z}$, relative intensity) $306\left(\mathrm{MH}^{+}, 100\right), 308\left(\mathrm{MH}^{+}, 31\right.$, chlorine isotope); HRESIMS calcd for $\mathrm{C}_{13} \mathrm{H}_{12} \mathrm{ClN}_{5} \mathrm{O}_{2}$ 306.0758, found 306.0755. 


\section{Steady-state Kinetic Assays and QR2 IC 50 $_{0}$ Value Determination}

The enzymatic activity of QR2 was determined using MTT [3-(4,5-dimethylthiazol-2yl)-2,5-diphenyltetrazolium bromide] and $\mathrm{NMeH}$ as substrates as previously described. ${ }^{10,35}$ Briefly, assays were run in a 96-well plate with a final assay volume of $200 \mu \mathrm{L}$ and the appearance of the reduced form of the MTT substrate, formazan, was monitored at $612 \mathrm{~nm}$. The assay was performed at $23{ }^{\circ} \mathrm{C}$ using a BioTek Synergy H1 Hybride multi-mode microplate reader. Each assay mixture contained $12 \mathrm{nM}$ QR2, $25 \mu \mathrm{M} \mathrm{NMeH}$, and $200 \mu \mathrm{M}$ MTT in a reaction buffer containing $100 \mathrm{mM} \mathrm{NaCl}, 50 \mathrm{mM}$ Tris, $\mathrm{pH} 7.5$ and $0.1 \%$ TritonX-100. All reactions were initiated by the addition of QR2. Initial slopes of the reactions $(\triangle \mathrm{OD} @ 612 \mathrm{~nm} / \mathrm{min})$ were measured and were used to calculate the initial rates of the reaction using a value of $11,300 \mathrm{M}^{-1} \mathrm{~cm}^{-1}$ for the molar extinction coefficient of MTT.

$\mathrm{IC}_{50}$ values were determined using the same assay as described above with the addition of inhibitor at varying concentrations. The concentration ranges of inhibitor utilized to derive the final $\mathrm{IC}_{50}$ values depended on the final potency of the inhibitor. Assays at each concentration of inhibitor were performed in triplicate and the average and standard deviations in the rate values were used to determine the $\mathrm{IC}_{50}$ value by calculating the $\%$ inhibition at each inhibitor concentration versus the negative control with zero inhibitor. These data were plotted as the percent inhibition versus inhibitor concentration. All data were fit to the equation: \% $\mathrm{I}=\left(\% \mathrm{Imax}\left[1+[\mathrm{I}] / \mathrm{I} \mathrm{IC}_{50}\right)\right]$ using non-linear regression in the Enzyme Kinetics Module of the program SigmPlot. $\mathrm{IC}_{50}$ and \% maximal inhibition values are reported along with their standard error in the fitted parameter.

\section{Crystallization and X-ray Structure Determination of QR2 Inhibitor Complexes}

QR2 was crystallized using our previously described methods with some modification. ${ }^{10,21,22,35}$ Briefly, the hanging-drop, vapor-diffusion method was used by setting up drops of $1 \mu \mathrm{L}$ of purified QR2 $(4 \mathrm{mg} / \mathrm{mL})$ and then adding a series of $1 \mu \mathrm{L}$ aliquots of reservoir solution that contained between 1.3 to $1.7 \mathrm{M}$ ammonium sulfate in $0.1 \mathrm{M}$ Bis-Tris buffer between $\mathrm{pH} 6.0$ to 7.0 , with $0.1 \mathrm{M} \mathrm{NaCl}, 5 \mathrm{mM}$ DTT and $12 \mu \mathrm{M}$ FAD. Diffraction quality, rod-shaped crystals grew within 1 week with dimensions of approximately $0.1 \mathrm{~mm} \times 0.2 \mathrm{~mm}$. Crystals were transferred from hanging-drops to a $10 \mu \mathrm{L}$ drop of an artificial mother-liquor solution prepared with $9 \mu \mathrm{L}$ reservoir solution and $1 \mu \mathrm{L}$ stock solution of inhibitor (10 mM in 100\% DMSO). Crystals were allowed to soak for 3 to $24 \mathrm{~h}$. Crystals were retrieved with a nylon loop, which was then swiped through the same artificial mother-liquor solution supplemented with $20 \%$ glycerol. The crystals were then flash-frozen by plunging into liquid nitrogen.

X-ray diffraction data were collected at beamline 21-ID-G at the Life Sciences Collaborative Access Team (LS-CAT) at the Advanced Photon Source (APS), Argonne National Laboratories. X-Ray data sets were collected on a MarMosaic $300 \mathrm{~mm}$ CCD detector. QR2inhibitor complexes of compound $\mathbf{2}$ and compound $\mathbf{3 8}$ were processed and scaled using the program HKL2000. ${ }^{36}$ The crystals belonged to the primitive orthorhombic space group $\mathrm{P} 2{ }_{1} 2{ }_{1}{ }_{1}$. Complete $\mathrm{X}$-ray data sets were obtained for 3 individual crystals of QR2 in complex with compound 38. X-ray data on compound 2 were collected to $1.53 \AA$ (1.53-1.56 $\AA$ ) where the data in parentheses represent the highest resolution shell for the QR2compound 2 complex. The overall completeness was $97.0 \%$ (79.2\%), the average I/ $\sigma \mathrm{I}$ was 31.7 (2.8) and the average mosaicity was $0.17^{\circ}$. Data on the QR2-38 complex were collected to $1.50 \AA$ ( $1.50-1.55 \AA$ ) resolution. The overall completeness was $99.6 \%$ (99.3\%), the average $\mathrm{I} / \sigma \mathrm{I}$ was $37.4(2.7)$, and the average mosaicity was $0.61^{\circ}$.

Intensities were converted to structure-factor amplitudes by the French and Wilson method using TRUNCATE in the CCP4 program suite. ${ }^{37}$ The initial phases for the model were 
determined by molecular replacement using the program PHASER in CCP4 using PDB 1SG0 as the search model. ${ }^{11}$ The final structure contained a dimer per asymmetric unit. Molecular library files and coordinates for the inhibitors were built using Sketcher in CCP4. Fourier maps were calculated and visualized using the program $\operatorname{Coot}^{31}$ and the structures were refined using the program Refmac. Water molecules were added manually to $2 \mathrm{Fo}-\mathrm{Fc}$ density peaks that were greater than $1.0 \sigma$. Iterative rounds of refinement using Refmac were continued until $\mathrm{R}_{\text {work }}$ and $\mathrm{R}_{\text {free }}$ values reached their lowest values. At this point, TLS refinement was employed using by first submitting the coordinates to the TLS (translation/ libration/screw) server ${ }^{38}$ to generate a multi-group TLS model. The resulting TLS groups were visualized using the molecular viewer on the TLS website, ${ }^{39}$ and 13 TLS groups were chosen. Two rounds of TLS and restrained refinement ${ }^{40}$ were performed in REFMAC to arrive at the final models that were then validated using MolProbity. ${ }^{41}$ The final model for the QR2-compound 2 complex was refined to a value of $16.2 \%$ for $\mathrm{R}_{\mathrm{work}}$ and $18.4 \%$ for

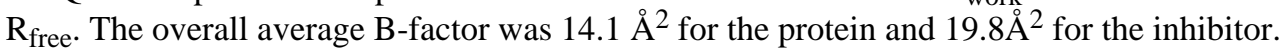
The X-ray structure for the QR2-compound 38 complex was refined to $17.9 \%$ for $\mathrm{R}_{\mathrm{work}}$ and $19.7 \%$ for $\mathrm{R}_{\text {free. }}$. The overall average B-factor was $15.8 \AA^{2}$ for the protein and $25.8 \AA^{2}$ for the inhibitor. Electron density maps presented in the figures were calculated using CCP4 and the figures were generated using the program PYMOL.

\section{Supplementary Material}

Refer to Web version on PubMed Central for supplementary material.

\section{Acknowledgments}

This work was facilitated by the National Institutes of Health (NIH) through support with Research Grant P01 CA48112. We wish to thank Dr. Karl Wood, Dr. Huaping Mo, and Dr. Daniel Lee for consultation and valuable discussions. We would like to also thank the Life-Sciences CAT staff for their help at beamline 21-ID G which was used for X-ray data collection. Use of the Advanced Photon Source was supported by the U. S. Department of Energy, Office of Science, Office of Basic Energy Sciences, under Contract No. DE-AC02-06CH11357. Use of the LS-CAT Sector 21 was supported by the Michigan Economic Development Corporation and the Michigan Technology Tri-Corridor for the support of this research program (Grant 085P1000817).

\section{Abbreviations used}

$\begin{array}{ll}\text { CIMS } & \text { chemical ionization mass spectrometry } \\ \text { DIPEA } & N, N \text {-diisopropylethylamine } \\ \text { DMF } & N, N \text {-dimethylformamide } \\ \text { DMSO } & \text { dimethyl sulfoxide } \\ \text { EIMS } & \text { electron impact mass spectrometry } \\ \text { ESIMS } & \text { electrospray ionization mass spectrometry } \\ \text { FAD } & \text { flavin adenine dinucleotide } \\ \text { HRMS } & \text { high resolution mass spectrometry } \\ \text { NCS } & N \text {-chlorosuccinimide } \\ \text { NMeH } & N \text {-methyldihydronicotinamide } \\ \text { PTSA } & p \text {-toluenesulfonic acid } \\ \text { QR2 } & \text { quinone reductase } 2 \\ \text { THF } & \text { tetrahydrofuran }\end{array}$




\section{References}

1. Guadêncio SP, MacMillan JB, Jensen PR, Fenical W. Ammosamides A and B New Cytotoxic Alkaloids Isolated from Marine Streptomyces sp. Planta Med. 2008; 74:1083.

2. Hughes CC, MacMillan JB, Gaudencio SR, Jensen PR, Fenical W. The Ammosamides: Structures of Cell Cycle Modulators from a Marine-Derived Streptomyces Species. Angewandte Chem. Int. Ed. 2009; 48:725-727.

3. Hughes CC, Fenical W. Total Synthesis of the Ammosamides. J. Am. Chem. Soc. 2010; 132:25282529. [PubMed: 20131899]

4. Hughes CC, MacMillan JB, Gaudencio SP, Fenical W, La Clair JJ. Ammosamides A and B Target Myosin. Angewandte Chem. Int. Ed. 2009; 48:728-732.

5. Reddy PVN, Banerjee B, Cushman M. Efficient Total Synthesis of Ammosamide B. Org. Lett. 2010; 12:3112-3114. [PubMed: 20515072]

6. Sturdy, M.; Pegan, S.; Gaudãncio, SP.; Mo, S.; Chlipala, G.; Orjala, J.; Fenical, W.; Mesecar, AD. Discovery of the Ammosamides as Quinone Reductase-2 Inhibitors Through Crystallographic Methods.; American Society of Pharmacognosy (ASP) Meeting; Honolulu, Hawaii. 2009;

7. Celli CM, Tran N, Knox R, Jaiswal AK. NRH:Quinone Oxidoreductase 2 (NQO2) Catalyzes Metabolic Activation of Quinones and Anti-tumor Drugs. Biochem. Pharmacol. 2006; 72:366-376. [PubMed: 16765324]

8. Jamieson D, Tung AT, Knox RJ, Boddy AV. Reduction of Mitomycin C Is Catalysed by Human Recombinant NRH:Quinone Oxidoreductase 2 Using Reduced Nicotinamide Adenine Dinucleotide As an Electron Donating Co-factor. Br. J. Cancer. 2006; 95:1229-1233. [PubMed: 17031400]

9. Knox RJ, Jenkins TC, Hobbs SM, Chen S, Melton RG, Burke PJ. Bioactivation of 5-(Aziridin-1yl)-2,4-dinitrobenzamide (CB 1954) by Human NAD(P)H Quinone Oxidoreductase 2: a Novel CoSubstrate-Mediated Antitumor Prodrug Therapy. Cancer Res. 2000; 60:4179-4186. [PubMed: 10945627]

10. Maiti A, Sturdy M, Marler L, Pegan SD, Mesecar AD, Pezzuto JM, Cushman M. Synthesis of Casimiroin and Optimization of Its Quinone Reductase 2 and Aromatase Inhibitory Activity. J. Med. Chem. 2009; 52:1873-1884. [PubMed: 19265439]

11. Buryanovskyy L, Fu Y, Boyd M, Ma YL, Hsieh TC, Wu JM, Zhang ZT. Crystal Structure of Quinone Reductase 2 in Complex with Resveratrol. Biochemistry. 2004; 43:11417-11426. [PubMed: 15350128]

12. Kwiek JJ, Haystead TAJ, Rudolph J. Kinetic Mechanism of Quinone Oxidoreductase 2 and Its Inhibition by the Antimalarial Quinolines. Biochemistry. 2004; 43:4538-4547. [PubMed: 15078100]

13. Mailliet F, Ferry G, Vella F, Berger S, Coge F, Chomarat P, Mallet C, Guenin SP, Guillaumet G, Viaud-Massuard MC, Yous S, Delagrange P, Boutin JA. Characterization of the Melatoninergic MT3 Binding Site on the NRH : Quinone Oxidoreductase 2 Enzyme. Biochem. Pharmacol. 2005; 71:74-88. [PubMed: 16293234]

14. Rix U, Hantschel O, Duernberger G, Rix LLR, Planyavsky M, Fernbach NV, Kaupe I, Bennett KL, Valent P, Colinge J, Kocher T, Superti-Furga G. Chemical Proteomic Profiles of the BCR-ABL Inhibitors Imatinib, Nilotinib, and Dasatinib, Reveal Novel Kinase and Nonkinase Targets. Blood. 2007; 110:4055-4063. [PubMed: 17720881]

15. Nolan KA, Humphries MP, Barnes J, Doncaster JR, Caraher MC, Tirelli N, Bryce RA, Whitehead RC, Stratford IJ. Triazoloacridin-6-ones as Novel Inhibitors of the Quinone Oxidoreductases NQO1 and NQO2. Bioorg. Med. Chem. 2010; 18:696-706. [PubMed: 20036559]

16. Boyer JH, Morgan LR. Conversion of 3-Aminocatechols to 6-Hydroxypicolinic Acids. Journal of the American Chemical Society. 1960; 82:4748-4749.

17. Sadighi JP, Harris MC, Buchwald SL. A Highly Active Palladium Catalyst for the Arylation of Anilines. Tetrahderon Lett. 1998; 39:5327-5330.

18. Ferry G, Hecht S, Berger S, Moulharat N, Coge F, Guillaumet G, Leclerc V, Yous S, Delagrange P, Boutin JA. Old and New Inhibitors of Quinone Reductase 2. Chem.-Biol. Interact. 2010; 186:103-109. [PubMed: 20399199] 
19. Graves PR, Kwiek JJ, Fadden P, Ray R, Hardeman K, Coley AM, Foley M, Haystead TAJ. Discovery of Novel Targets of Quinoline Drugs in the Human Purine Binding Proteome. Mol. Pharmacol. 2002; 62:1364-1372. [PubMed: 12435804]

20. Dunstan MS, Barnes J, Humphries M, Whitehead RC, Bryce RA, Leys D, Stratford IJ, Nolan KA. Novel Inhibitors of NRH:Quinone Oxidoreductase 2 (NQO2): Crystal Structures, Biochemical Activity, and Intracellular Effects of Inidazoaciidin-6-ones. J. Med. Chem. 2011 (ASAP).

21. Calamini B, Santarsiero BD, Boutin JA, Mesecar AD. Kinetic, Thermodynamic and X-Ray Structural Insights into the Interaction of Melatonin and Analogues with Quinone Reductase 2. Biochem. J. 2008; 413:81-91. [PubMed: 18254726]

22. Pegan SD, Sturdy M, Ferry G, Delagrange P, Boutin JA, Mesecar AD. X-Ray Structural Studies of Quinone Reductase 2 Nanomolar Range Inhibitors. Protein Sci. 2011; 20:1182-1195. [PubMed: 21538647]

23. Winger JA, Hantschel O, Superti-Furga G, Kuriyan J. The Structure of the Leukemia Drug Imatinib Bound to Human Quinone Reductase 2 (NQO2). BMT Struct. Biol. 2009:9.

24. AbuKhader M, Heap J, De Matteis C, Kellam B, Doughty SW, Minton N, Paoli M. Binding of the Anticancer Prodrug CB1954 to the Activating Enzyme NQO2 Revealed by the Crystal Structure of Their Complex. J. Med. Chem. 2005; 48:7714-7719. [PubMed: 16302811]

25. Fu Y, Buryanovskyy L, Zhang ZT. Crystal Structure of Quinone Reductase 2 in Complex with Cancer Prodrug CB1954. Biochem. Biophys. Res. Commun. 2004; 336:332-338. [PubMed: 16129418]

26. Fu Y, Buryanovskyy L, Zhang ZT. Quinone Reductase 2 Is a Catechol Quinone Reductase. J. Biol. Chem. 2008; 283:23829-23835. [PubMed: 18579530]

27. Dietz BM, Kang YH, Liu GW, Eggler AL, Yao P, Chadwick LR, Pauli GF, Farnsworth NR, Mesecar AD, van Breemen RB, Bolton JL. Xanthohumol Isolated from Humulus lupulus Inhibits Menadione-Induced DNA Damage through Induction of Quinone Reductase. Chem. Res. Toxicol. 2005; 18:1296-1305. [PubMed: 16097803]

28. Iskra J, Stavber S, Zupan M. Nonmetal-catalyzed Iodination of Arenes with Iodide and Hydrogen Peroxide. Synthesis. 2004:1869-1873.

29. Boyd MR. Status of the NCI Preclinical Antitumor Drug Discovery Screen. Principles and Practices of Oncology. 1989; 3:1-12.

30. Dreyer GB, Metcalf BW, Tomaszek TA Jr. Carr TJ, Chandler AC III, Hyland L, Fakhoury SA, Magaard VW, Moore ML, Strickler JE, Debouck C, Meek TD. Inhibition of Human Immunodeficience Virus 1 Protease In Vitro: Rational Design of Substrate Analogue Inhibitors. Proc. Natl. Acad. Sci. U.S.A. 1989; 86:9752-9756. [PubMed: 2690072]

31. Emsley P, Cowtan K. Coot: Model-Building Tools for Molecular Graphics. Acta Crystallogr. Sect. D: Biol. Crystallogr. 2004; 60:2126-2132. [PubMed: 15572765]

32. Hsieh TC. Uptake of Resveratrol and Role of Resveratrol-targeting Protein, Quinone Reductase 2, in Normally Cultured Human Prostate Cells. Asian J. of Androl. 2009; 11:653-661. [PubMed: 19767760]

33. Wang Z, Hsieh T, Zhang Z, Ma Y, Wu JM. Identification and Purification of Resveratrol Targeting Proteins Using Immobilized Resveratrol Affinity Chromatography. Biochem. Biophys. Res. Commun. 2004; 323:743-749. [PubMed: 15381063]

34. Sun B, Hoshino J, Jermihov K, Marler L, Pezzuto JM, Mesecar AD, Cushman M. Design, Synthesis, and Biological Evaluation of Resveratrol Analogues as Aromatase and Quinone Reductase 2 Inhibitors for Chemoprevention of Cancer. Bioorg. Med. Chem. 2010; 18:5352-5366. [PubMed: 20558073]

35. Conda-Sheridan M, Marler L, Park EJ, Kondratyuk TP, Jermihov K, Mesecar AD, Pezzuto JM, Asolkar RN, Fenical W, Cushman M. Potential Chemopreventive Agents Based on the Structure of the Lead Compound 2-Bromo-1-hydroxyphenazine, Isolated from Streptomyces Species, Strain CNS284. J. Med. Chem. 2010; 53:8688-8699. [PubMed: 21105712]

36. Otwinowski Z, Minor Z. Processing of X-Ray Diffraction Data Collected in Oscillation Mode. Methods Enzymol. 1997; 276:307-326.

37. Collaborative Computational Project, N. The CCP4 Suite: Programs for Protein Crystallography. Acta Cryst. 1994; D50:760-763. 
38. Painter J, Merritt EA. TLSMD Web Server for the Generation of Multi-group TLS Models. J. Appl. Crystallogr. 2006; 39:109-111.

39. Painter J, Merritt EA. A Molecular Viewer for the Analysis of TLS Rigid-body Motion in Macromolecules. Acta Crystallogr. D Biol. Crystallogr. 2005; 61:465-471.

40. Winn MD, Isupov MN, Murshudov GN. Use of TLS Parameters to Model Anisotropic Displacements in Macromolecular Refinement. Acta Crystallogr. D Biol. Crystallogr. 2001; 57:122-133. [PubMed: 11134934]

41. Lovell SC, Davis IW, Adrendall WB, de Bakker PIW, Word JM, Prisant MG, Richardson JS, Richardson DC. Structure Validation by C Alpha Geometry: Phi,Psi and C Beta Deviation. Proteins: Struct., Funct., Genet. 2003; 50:437-450. [PubMed: 12557186] 

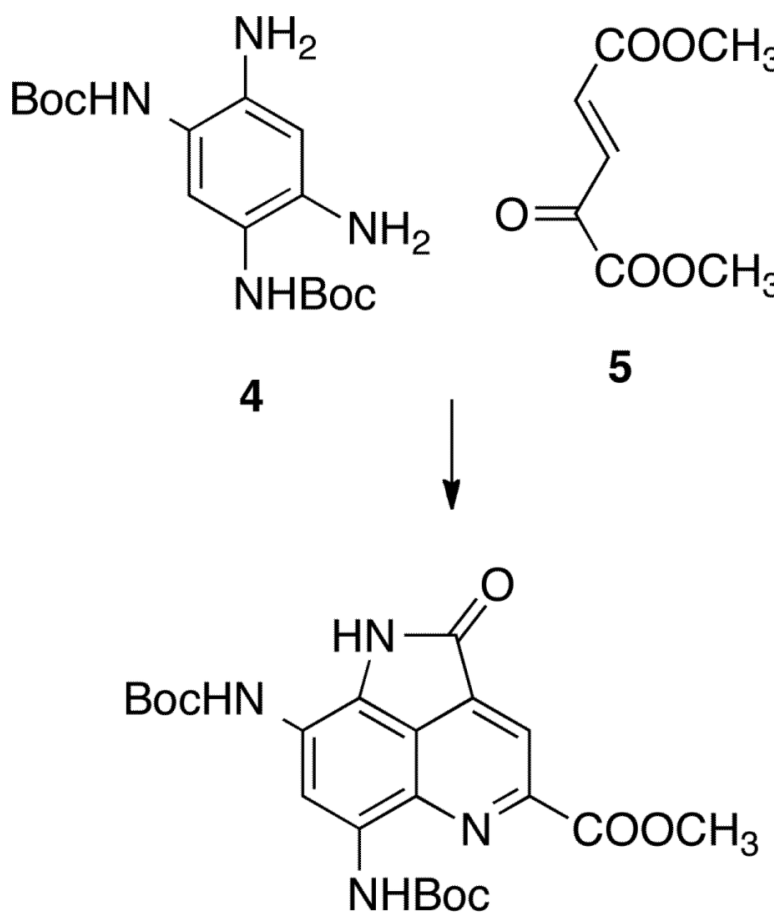

6

Scheme 1.

Approach to the Synthesis of the Ammosamides 
<smiles>COC(=O)c1cc(C(C)=O)c2c(Cl)cc(N(C)C)cc2n1</smiles>

15<smiles>COC(=O)c1cc(C(=O)OC)c2c(Cl)cc(NC(=O)OC(C)(C)C)cc2n1</smiles>

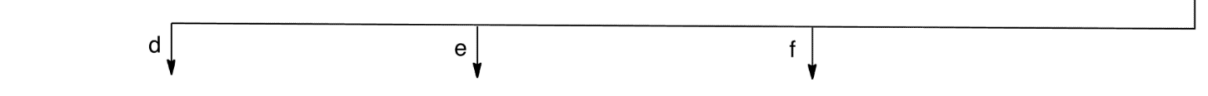<smiles>COC(=O)c1cc(C(=O)OC)c2c(Cl)cc(N)cc2n1</smiles>

11<smiles>CC(=O)Nc1cc(Cl)c2c(C(C)=O)cc(C(C)=O)nc2c1</smiles>

13<smiles>CC(=O)Nc1cc(Cl)c2c(C(C)=O)cc(C(N)=O)nc2c1</smiles>

14

aReagents and conditions: (a) benzyl chloroformate, DIPEA, $\mathrm{CH}_{2} \mathrm{Cl}_{2}$ room temperature ( $24 \mathrm{~h}$ ); (b) compound $\mathbf{5}$, PTSA, $\mathrm{CH}_{2} \mathrm{Cl}_{2}, 40{ }^{\circ} \mathrm{C}(24 \mathrm{~h})$; (c) $\mathrm{H}_{2}, \mathrm{Pd} / \mathrm{C}, \mathrm{CH}_{3} \mathrm{OH}$, room temperature (1 h); (d) $\mathrm{NCS}, \mathrm{CH}_{3} \mathrm{CN}, 65^{\circ} \mathrm{C}(2 \mathrm{~h})(2 \mathrm{~h})$; (e) $\mathrm{NH}_{4} \mathrm{OH}, \mathrm{THF}$, room temperture (24 h); (f) $\mathrm{Ac}_{2} \mathrm{O}, \mathrm{DMAP}, \mathrm{CH}_{2} \mathrm{Cl}_{2}$, room temperature (2 h); (g) $\mathrm{NaH}, \mathrm{CH}_{3} \mathrm{I}, \mathrm{DMF}$, room temperature $(24 \mathrm{~h})$.

Scheme 2.

Synthesis of Ammosamide Analogues 9-16 
<smiles>COC(=O)c1cc(C(C)=O)nc2cc(N)c(I)cc12</smiles>

17<smiles>CC(=O)c1cc(C(N)=O)nc2cc(N)c(I)cc12</smiles>

aReagents and conditions: (a) (1) compound $\mathbf{5}$, $\mathrm{CH}_{2} \mathrm{Cl}_{2}$, room temperature (30 min), (2) PTSA, $\mathrm{Cu}(\mathrm{OAc})_{2}$, reflux (24 h); (b) $\mathrm{NH}_{4} \mathrm{OH}, \mathrm{THF}, 70$ ${ }^{\circ} \mathrm{C}(24 \mathrm{~h})$.

Scheme 3.

Synthesis of Ammosamide Analogues 18-20a 
<smiles>Nc1cc(N)c(N)c(Cl)c1</smiles>

21<smiles>COC(=O)c1cc(C(=O)OC)c2c(Cl)c(N)c(N)cc2n1</smiles>

22

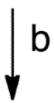<smiles>CC(=O)c1cc(C(N)=O)nc2cc(N)c(N)c(Cl)c12</smiles>

aReagents and conditions: (a) (1) compound $\mathbf{5}$, $\mathrm{CH}_{2} \mathrm{Cl}_{2}$, room temperature (30 $\left.\mathrm{min}\right)$, (2) PTSA, $\mathrm{Cu}(\mathrm{OAc})_{2}$, reflux (24 h); (b) $\mathrm{NH}_{4} \mathrm{OH}$, THF, room temperature $(24 \mathrm{~h})$.

Scheme 4.

Synthesis of Ammosamide Analogue 23a 
<smiles>O=[N+]([O-])c1cc([N+](=O)[O-])c(Cl)cc1Cl</smiles>

24<smiles>Nc1cc(Cl)c(Cl)cc1N</smiles>

25<smiles>COC(=O)C1CC(O)(C(C)=[IH])c2c(N)c(Cl)cc(Cl)c2N1</smiles>

26<smiles>CC(=O)C1CC2(O)C(=O)Nc3c(Cl)cc(Cl)c(c32)N1</smiles>

33<smiles>COC(=O)c1cc2c3c(c(Cl)cc(Cl)c3n1)N(C)C2=O</smiles><smiles>CC(=O)c1cc2c3c(c(Cl)cc(Cl)c3n1)NC2=O</smiles>

28<smiles>CC(=O)c1cc2c3c(n1)C(=O)C(=O)C(Cl)=C3N(C)C2=O</smiles><smiles>CN1C(=O)c2cc(C(N)=O)nc3c(Cl)cc(Cl)c1c23</smiles><smiles></smiles><smiles>CNC(=O)c1cc2c3c(c(Cl)cc(Cl)c3n1)N(C)C2=O</smiles>

31<smiles>Cc1ccccc1</smiles>

Reagents and conditions. (a) $\mathrm{Fe}, \mathrm{NH}_{4} \mathrm{Cl}, \mathrm{DMF} / \mathrm{H}_{2} \mathrm{O}, 100{ }^{\circ} \mathrm{C}$; (b) (1) compound 5, $\mathrm{CH}_{2} \mathrm{Cl}_{2}$, room temperature (30 min), (2) PTSA, $\mathrm{Cu}(\mathrm{OAc})_{2}, 40{ }^{\circ} \mathrm{C}, 24 \mathrm{~h}, 65 \%$; (c) $\mathrm{SOCl}_{2}, 90{ }^{\circ} \mathrm{C}$ (3 h); (d) $\mathrm{Et}_{3} \mathrm{~N}$, $\mathrm{CH}_{2} \mathrm{Cl}_{2}$, room temperature (24 h); (e) $\mathrm{NaH}, \mathrm{CH}_{3} \mathrm{I}, \mathrm{DMF}, 90{ }^{\circ} \mathrm{C}(1 \mathrm{~h})$; (f) $30 \% \mathrm{NH}_{4} \mathrm{OH}, \mathrm{THF}$, room temperature $(24 \mathrm{~h})$; $(\mathrm{g}) \mathrm{BuLi}, \mathrm{BnBr}, \mathrm{THF},-78{ }^{\circ} \mathrm{C}(3 \mathrm{~h})$; (h) $\mathrm{CH}_{3} \mathrm{I}, \mathrm{NaH}$, DMF, room temperature (1 h); (i) $\mathrm{NaH}$, THF, room temperature (15 min); (j) $\mathrm{HNO}_{3}, \mathrm{H}_{2} \mathrm{SO}_{4}$, room temperature $(1 \mathrm{~h})$.

Scheme 5.

Synthesis of Ammosamide Analogues 27-34a 
<smiles>CC(=O)c1cc2c3c(c(N)c(Cl)c(N)c3n1)NC2=O</smiles>

35<smiles>CNc1c(Cl)c(N)c2c3c(cc(C(N)=O)nc13)C(=O)N2C</smiles>

aReagents and conditions: (a) $\mathrm{NaH}, \mathrm{CH}_{3} \mathrm{I}, \mathrm{DMF}, 23{ }^{\circ} \mathrm{C}, 1$ h; (b) $30 \%$ aq $\mathrm{NH}_{4} \mathrm{OH}$, THF $23{ }^{\circ} \mathrm{C}, 24 \mathrm{~h}$.

Scheme 6.

Synthesis of Ammosamides Anaglogue $\mathbf{3 8}^{\mathbf{a}}$ 
(A)

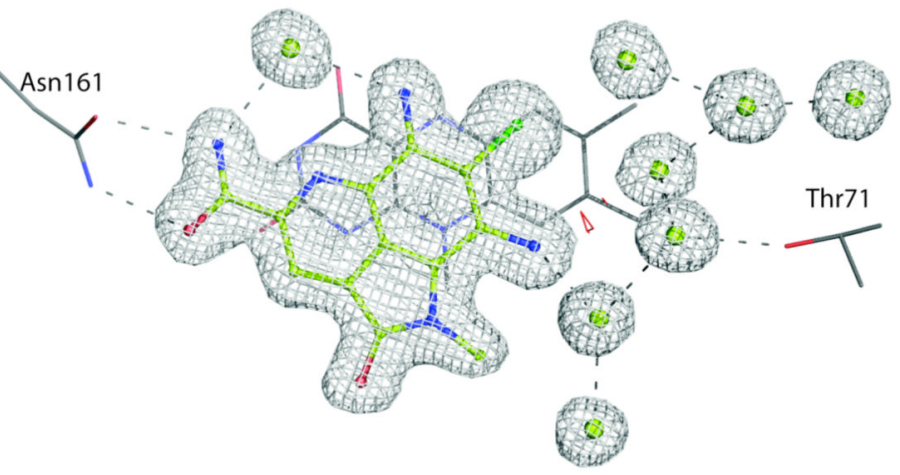

(B)

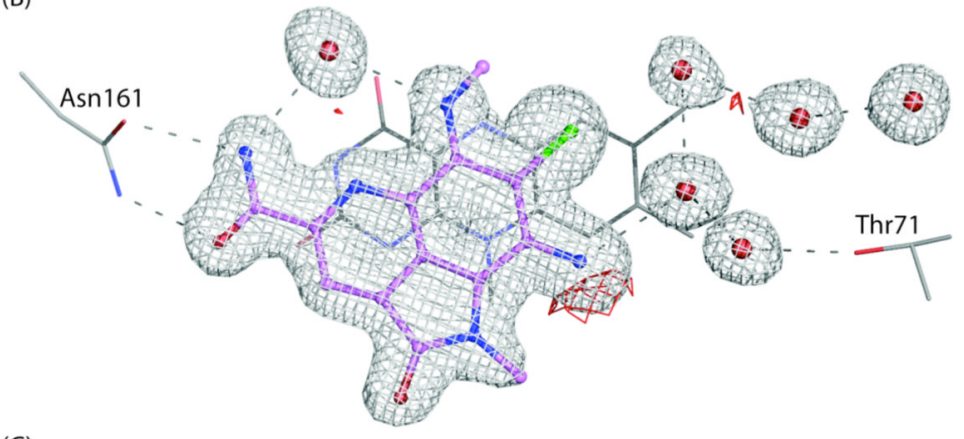

(C)

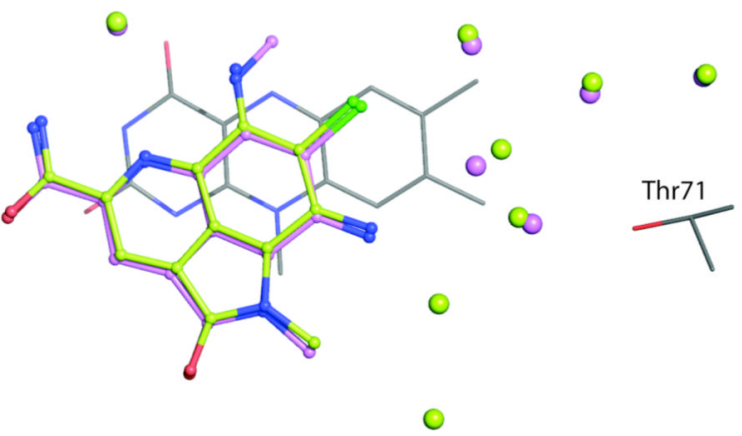

Figure 1.

X-ray crystal structures of ammosamide B (2) and compound 38 in complex with QR2. Ligands are shown in ball and stick and colored according to atom type. Water molecules are shown as solid spheres and hydrogen bonds are shown in grey dashes (2.8-3.4 $\AA$ ). Electron density maps $(2 \mathrm{Fo}-\mathrm{Fc})$ are contoured to $1.0 \sigma$ and shown in grey mesh. Electron density difference maps (Fo-Fc) are contoured to $3.0 \sigma$ and are shown in red mesh. The binding orientation of the ligands are the same in both active sites of the dimer and therefore for simplicity, only the inhibitors in the A-chain active site are shown. (A) X-ray structure of QR2 in complex with compound 2. (B) X-ray structure of QR2 in complex with compound 38. (C) Superposition of the X-ray structures shown in A and B with the colors of inhibitors conserved. Active site water molecules correspond to compound coloring. Fo-Fc Electron density omit maps for ammosamide B and compound $\mathbf{3 8}$ are provided in Supporting Information, Figure S3. 


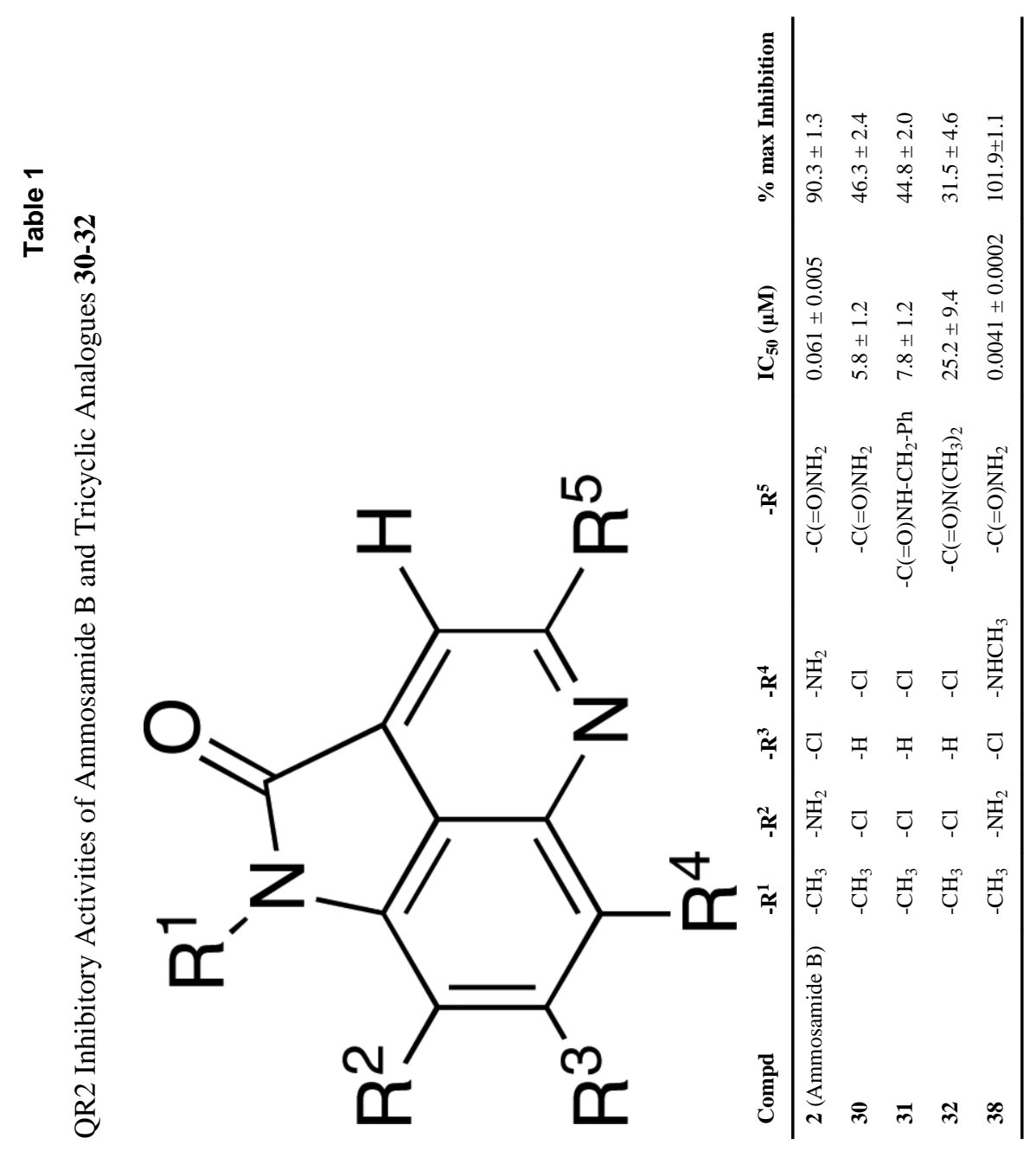

J Med Chem. Author manuscript; available in PMC 2013 January 12. 


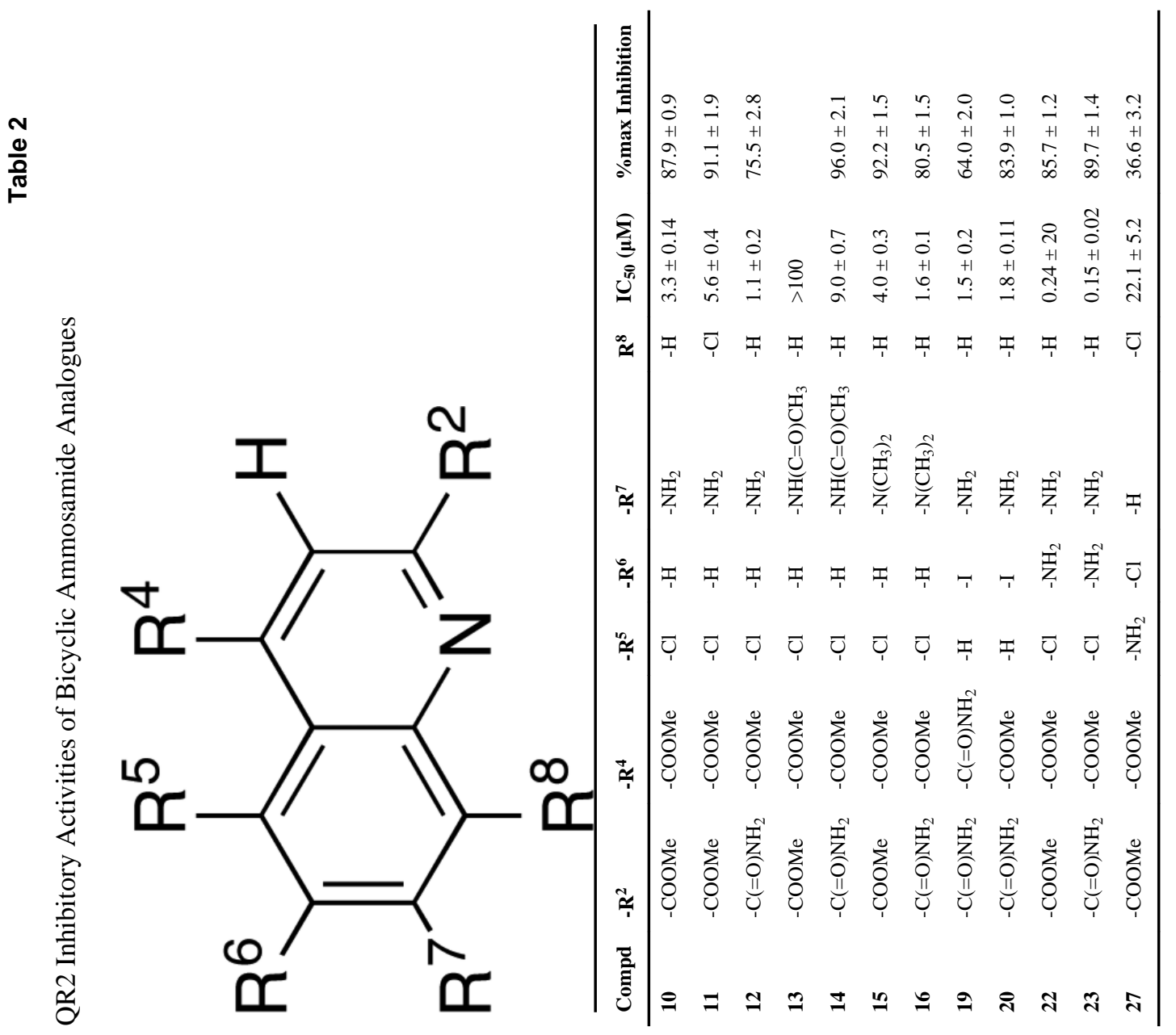

J Med Chem. Author manuscript; available in PMC 2013 January 12. 
